ARTICLE

https://doi.org/10.1038/s41467-020-15858-w

\title{
Real-time monitoring of PARP1-dependent PARylation by ATR-FTIR spectroscopy
}

Annika Krüger ${ }^{1,2}$, Alexander Bürkle $^{1}$, Karin Hauser $^{2 凶} \&$ Aswin Mangerich (1D ${ }^{1 凶}$

Poly-ADP-ribosylation (PARylation) is a fully reversible post-translational modification with key roles in cellular physiology. Due to the multi-domain structure of poly(ADP-ribose) polymerase-1 (PARP1) and the highly dynamic nature of the PARylation reaction, studies on the biochemical mechanism and structural dynamics remain challenging. Here, we report label-free, time-resolved monitoring of PARP1-dependent PARylation using ATR-FTIR spectroscopy. This includes PARP1 activation by binding to DNA strand break models, NAD+ substrate binding, PAR formation, and dissociation of automodified PARP1 from DNA. Analyses of PARP1 activation at different DNA models demonstrate a strong positive correlation of PARylation and PARP1 dissociation, with the strongest effects observed for DNA nicks and 3' phosphorylated ends. Moreover, by examining dynamic structural changes of PARP1, we reveal changes in the secondary structure of PARP1 induced by NAD ${ }^{+}$and PARP inhibitor binding. In summary, this approach enables holistic and dynamic insights into PARP1dependent PARylation with molecular and temporal resolution.

\footnotetext{
${ }^{1}$ Department of Biology, University of Konstanz, Konstanz 78464, Germany. ${ }^{2}$ Department of Chemistry, University of Konstanz, Konstanz 78464, Germany.

凶email: karin.hauser@uni-konstanz.de; aswin.mangerich@uni-konstanz.de
} 
F ast and efficient cellular DNA repair is essential to ensure genomic integrity over time. One of the first signalling events upon DNA damage is the recruitment of poly(ADPribose) polymerase-1 (PARP1) to sites of DNA damage, in particular DNA strand breaks. In this very fast process, PARP1 association rates of $10^{9} \mathrm{M}^{-1} \mathrm{~s}^{-1}$ have been reported ${ }^{1}$. The catalytic activation of PARP1 and resulting formation of poly(ADPribose) (PAR) from $\mathrm{NAD}^{+}$contributes to the repair of DNA lesions, stabilisation of replication forks and chromatin remodelling $^{2}$. PAR molecules are formed by attachment of ADP-ribose units via unique ribose-ribose linkages resulting in linear and branched PAR chains, which are heterogeneous in size and branching frequencies comprising up to $200 \mathrm{ADP}$-ribose units. Initiation of PAR synthesis occurs at several amino acids in target proteins, including serine, glutamate, aspartate, lysine and tyrosine $\mathrm{e}^{3,4}$. So far, hundreds of proteins have been identified as targets of covalent PARylation, with PARP1 being the prime target itself ${ }^{5-7}$. It is generally assumed that automodification of PARP1 results in steric and electrostatic repulsion and thereby in the release of PARP1 from DNA, giving access to other repair factors $^{8-11}$

PARP1, together with PARP2 and PARP3, belongs to the group of DNA-dependent PARPs ${ }^{12}$. PARP1 is activated at several different DNA structures, including single- and double-strand breaks, hairpins, cruciforms and stably unpaired regions $\mathrm{s}^{8,13-17}$. Neither sequence specificity nor clear preferences for any DNA strand break structure have been observed so far. DNA binding is mediated via the N-terminal DNA-binding domain of PARP1 consisting of two DNA-binding zinc-fingers ( $\mathrm{ZnF} 1$ and $\mathrm{ZnF} 2$ ) (Supplementary Fig. 1a). A third zinc finger $(\mathrm{ZnF} 3)$ is located adjacent of $\mathrm{ZnF} 2$, and is involved in the functional regulation of PARP1 activity. The structural mechanism behind DNA binding has been solved by crystal and NMR structures of the ZnFs in complex with different types of DNA strand breaks ${ }^{13,18-21}$. Even though $\mathrm{ZnF} 1, \mathrm{ZnF} 2$ and $\mathrm{ZnF} 3$ contact DNA directly, only $\mathrm{ZnF} 1$ and $\mathrm{ZnF} 3$ are essential for PARP1 activation $13,14,22$. Robust activation of PARP1 furthermore relies on the conserved Trp-Gly-Arg (WGR) domain and the catalytic domain, consisting of the autoinhibitory helical domain (HD) and the ADPribosyl transferase (ART) domain (Supplementary Fig. 1a). The BRCA1 C-terminal (BRCT) domain, which is a major site of automodification and which mediates protein-protein interactions, is not essential for PARP1 activity in vitro ${ }^{23-26}$. Under nonactivated conditions, the HD, which consists of six $\alpha$-helices that form a hydrophobic core, blocks binding of $\mathrm{NAD}^{+}$to the active site $^{27}$. Upon DNA binding, PARP1 undergoes a multi-domain allosteric switch, resulting in structural distortions of the $\mathrm{HD}$, and thereby the catalytic centre of the ART domain becomes accessible for $\mathrm{NAD}^{+14,22,26-28}$. While earlier data suggested a dimeric action of PARP1 and thereby a modification of PARP1 molecules in $\operatorname{trans}^{29,30}$, recent data supported the notion of a monomeric

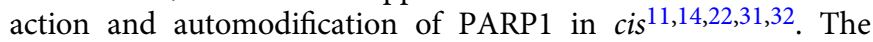
donor site, where $\mathrm{NAD}^{+}$binds, is highly conserved among PARPs. It includes a nicotinamide-binding pocket, a phosphate binding site and an adenine-ribose-binding site. The nicotinamide-binding pocket is also the site, where most pharmacological PARP inhibitors bind (Supplementary Fig. 1a). Recently, the first crystal structure of the human catalytic PARP1 domain in complex with a $\mathrm{NAD}^{+}$analogue has been solved ${ }^{27}$.

Even though PARP1 was discovered more than five decades $\mathrm{ago}^{12}$, the dynamics of the PARylation reaction and consequences on PARP1 structure are still incompletely understood. While DNA binding and subsequent PARP1 activation have been studied extensively $14,22,26-28$, data on changes in PARP1 structure upon $\mathrm{NAD}^{+}$binding and PARylation are largely missing. Moreover, the interplay of DNA strand break recognition by
PARP1 and its dissociation upon PARylation have not been explored in detail. Since it is difficult to study large and flexible proteins using conventional methods, innovative methodologies are needed to overcome these limitations. ATR-FTIR spectroscopy is a very sensitive method suitable to study large and flexible proteins under near-physiological conditions ${ }^{33,34}$. Performing reaction-induced difference spectroscopy enables monitoring of small structural changes of proteins upon molecular interactions or enzymatic reactions in real time. The specific immobilisation of molecules of interest at the ATR-crystal surface enhances the local surface concentration and thus improves the signal-to-noise ratio even at low analyte concentrations, thus providing an excellent platform to study the molecular mechanisms of PARylation.

Here, we apply a recently developed ATR-FTIR spectroscopic approach combining surface passivation and specific immobilisation ${ }^{35,36}$. By immobilising various biotinylated DNA strand break-mimicking oligonucleotides via streptavidin at the crystal surface, we study the dynamic interplay of PARP1 binding to DNA strand breaks, its subsequent catalytic activation, i.e., PARylation and the subsequent dissociation from DNA (Fig. 1a, b). Time-resolved monitoring enables the direct tracking of the enzymatic reaction and gives access to kinetic parameters as well as structural data on PARP1. We show that PARylation and PARP1 dissociation from DNA are interdependent processes, and that kinetics and efficiencies are determined by the substrate availability and the specific DNA strand break structure. Moreover, we unravel small but distinct structural changes of PARP1 upon addition of $\mathrm{NAD}^{+}$, which so far could not be monitored due to the fast catalytic turnover of $\mathrm{NAD}^{+}$. Taken together, this study provides direct and holistic insights into the molecular mechanisms underlying PARP1-dependent PARylation in a timeresolved manner.

\section{Results}

Binding of PARP1 to DNA strand breaks. PARP1 can be activated by various types of DNA structures, including single- and double-strand breaks, single-strand overhangs, hairpins and three- or four-way junctions ${ }^{8,13-16,37}$. Recently, it has been shown that while PARP2 and PARP3 are preferentially activated by DNA strand breaks harbouring a $5^{\prime}$ phosphate, PARP1 does not show a clear preference for any type of strand break ${ }^{8}$. To gain more insights into the DNA-binding properties of PARP1, we analysed the interaction of PARP1 with different types of DNA strand break-mimicking oligonucleotides via ATR-FTIR spectroscopy. To this end, we immobilised such biotinylated DNA oligonucleotides containing either a blunt (DNA blunt $)$, a $5^{\prime}$ phosphorylated $\left(\mathrm{DNA}_{5}{ }^{\prime} \mathrm{P}\right)$ or a $3^{\prime}$ phosphorylated ( $\left.\mathrm{DNA}_{3}{ }^{\prime} \mathrm{P}\right)$ double-strand break or a single nick $\left(\mathrm{DNA}_{\text {nick }}\right)$ via streptavidin on the modified crystal surface (Fig. 1a). The infrared spectra of the immobilised DNA oligonucleotides displayed the same position of the anti-symmetric phosphate vibration band at $1220 \mathrm{~cm}^{-1}$ (Supplementary Fig. 1b). This band is sensitive to the DNA secondary structure, and indicates that all DNA oligonucleotides exhibit a B-DNA structure ${ }^{38}$. Next, we added PARP1 to the respective immobilised DNA oligonucleotide and monitored the binding process as a function of time. PARP1 signals increased rapidly within the first minute, and reached saturation after $\sim 10$ min (Fig. 2a, b; Supplementary Fig. 1d). Calculated rate constants were similar for all DNA oligonucleotides, but binding of PARP1 to DNA $_{\text {blunt }}$ was slightly slower. Importantly, PARP1 bound specifically to the immobilised oligonucleotides, as no binding was observed to immobilised streptavidin alone (Supplementary Fig. 1c). We further analysed the amount of PARP1, which was bound to the respective DNA oligonucleotide (Fig. 2c). 
a

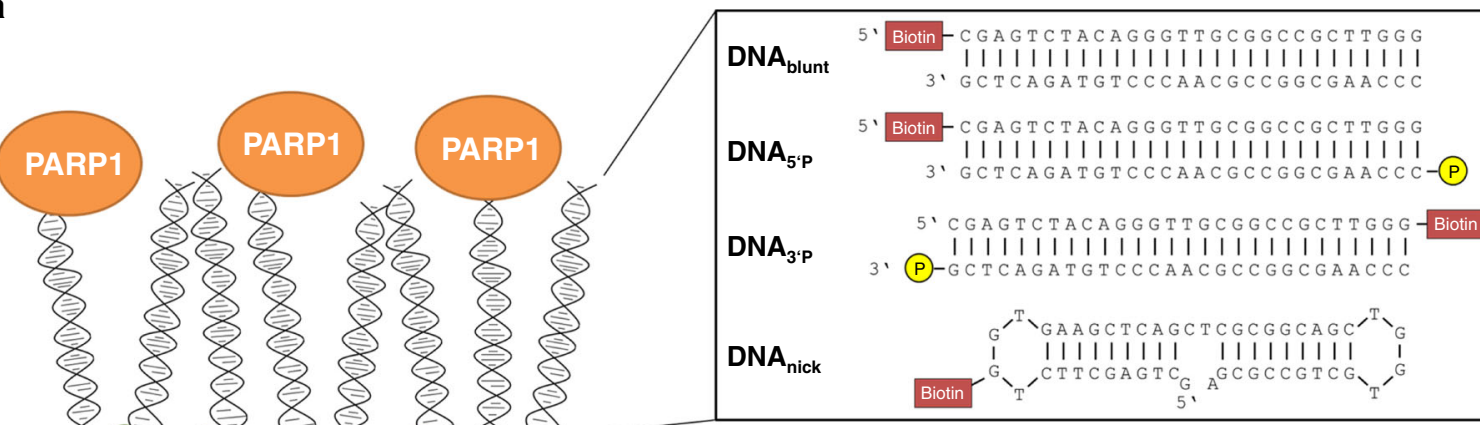

Streptavidin

Biotin

PEG-linker

Si-crystal

b

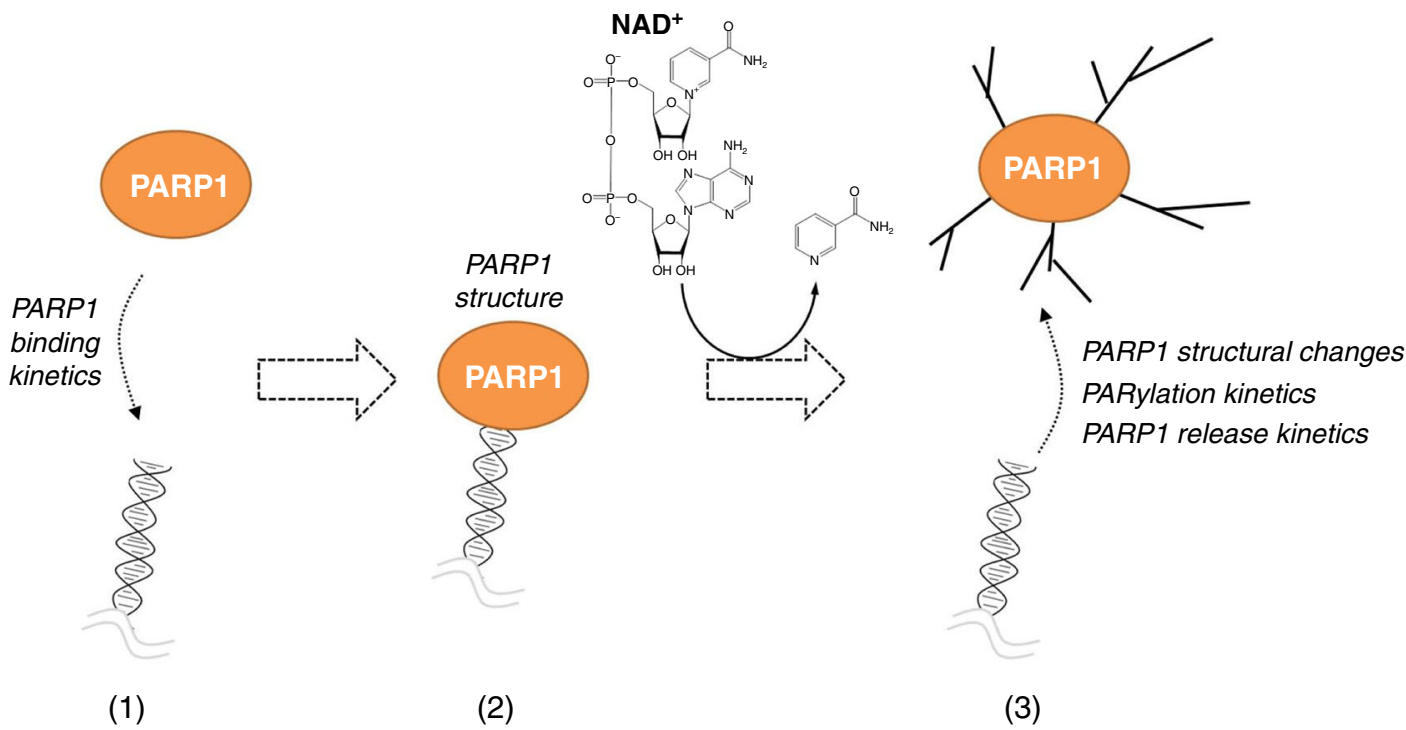

Fig. 1 Experimental setup. a Schematic representation of the ATR-FTIR spectroscopic setup. The silicon crystal surface was modified with PEG linkers to prevent unspecific protein adsorption. Biotinylated DNA strand break-mimicking oligonucleotides including $D N A_{\text {blunt }}, D N A_{5^{\prime} P}, D N A_{3^{\prime} P}$ and $D N A_{\text {nick }}$ were immobilised via streptavidin at the modified surface to study their interaction with PARP1. b Real-time monitoring of each step by ATR-FTIR spectroscopy allows to study various parameters: (1) PARP1-DNA-binding kinetics; (2) secondary structure of PARP1 bound to DNA; (3) structural changes of PARP1 upon $\mathrm{NAD}^{+}$addition, kinetics of PARylation and the resulting dissociation of PARP1 from DNA.

As $\mathrm{K}_{\mathrm{d}}$-values of PARP1 binding to DNA oligonucleotides are in the $\mathrm{nM}$ range (DNA blunt $7.6 \mathrm{nM}$ and $\mathrm{DNA}_{5}$, $6.2 \mathrm{nM}^{39}$ ), a complete saturation of binding sites can be assumed at the applied PARP1 concentration of $2 \mu \mathrm{M}$. We did not detect major differences in the amount of bound PARP1, suggesting that the stoichiometry of PARP1-DNA binding is comparable for all tested DNA oligonucleotides. It has been postulated that the binding of PARP1 to DNA strand breaks triggers its allosteric activation leading to structural changes within the $\mathrm{HD}$ domain, thereby enhancing accessibility of $\mathrm{NAD}^{+}$to the catalytic cleft ${ }^{40,41}$. To test if different types of DNA strand break structures impact the allosteric activation of PARP1, we analysed the secondary structure of PARP1 bound to the immobilised DNA strand break models. In particular, we generated difference spectra of PARP1 bound to $\mathrm{DNA}_{\text {blunt }}, \mathrm{DNA}_{5}{ }^{\prime} \mathrm{P}, \mathrm{DNA}_{3^{\prime} \mathrm{P}}$ or $\mathrm{DNA}_{\text {nick}}$, respectively (Fig. 2d). This method eliminates all vibrational modes in the spectra that do not change and thus uncovers explicitly all structural changes taking place. None of the three difference spectra displayed substantial positive or negative bands, suggesting that PARP1 has the same secondary structure when bound to the different DNA structures. In summary, the ATRFTIR approach allows real-time monitoring of binding of PARP1 to different DNA strand break models. Binding kinetics, stoichiometry and secondary structure of PARP1 appear to be independent of the type of DNA strand break structure.

Real-time monitoring of PARP1-dependent PARylation. DNA damage dependent PARylation by PARP1 is a very fast and dynamic process, which includes $\mathrm{NAD}^{+}$binding, PAR synthesis and dissociation of auto-modified PARP1 from DNA ${ }^{41}$. So far, most methods revealed a snapshot of each process, however, detailed insights into the dynamic interplay between the individual processes are still missing. Using the ATR-FTIR spectroscopic approach, we monitored the dynamic process of PARP1dependent PARylation in real time ${ }^{35,36}$. To lay the foundation for the spectral analysis of the catalytic reaction, we first compared the spectrum of $\mathrm{NAD}^{+}$to the one of ADP-ribose (Fig. 3a), which 

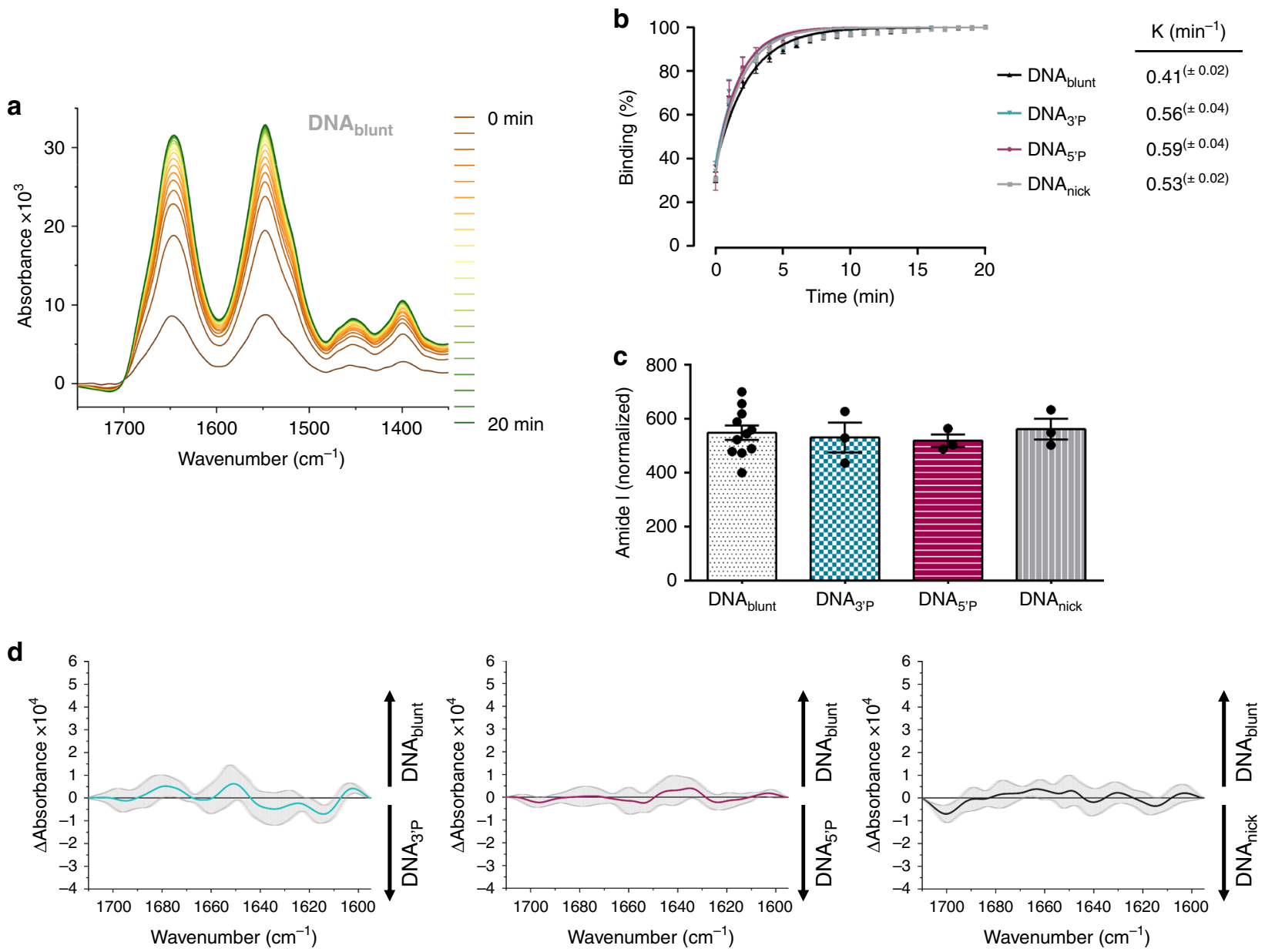

Fig. 2 Binding of PARP1 to DNA strand break-mimicking oligonucleotides. a Representative time-dependent spectra of PARP1 binding to immobilised DNA blunt. $_{\mathbf{b}} \mathbf{b}$ Evaluation of time-dependent binding of PARP1 to different types of DNA strand breaks. '0 min' refers to the first time point measured. Signal intensities of amide I bands $\left(1645 \mathrm{~cm}^{-1}\right)$ at 20 min were set to $100 \%$. Binding kinetics were calculated via a mono-exponential fit function. c Comparison of the amount of PARP1 bound to different types of DNA stand breaks after $20 \mathrm{~min}$ of co-incubation. Amide I bands $\left(1645 \mathrm{~cm}^{-1}\right)$ were normalised to the

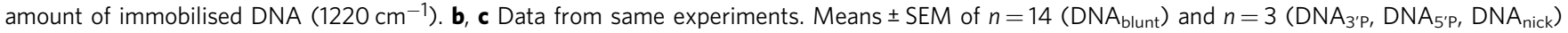
independent experiments, respectively. $\mathbf{d}$ Secondary structure analysis. Difference spectra of amide I bands of PARP1 bound to DNA $A_{\text {blunt }}$ and DNA $A_{3^{\prime} P}$, $D_{N A_{5} P}$ or $D N A_{\text {nick }}$ were calculated. Average curves and SD (grey) of nine difference spectra are plotted ( $n=3$ independent experiments, respectively). Source data are provided as a Source Data file.

exhibits an almost identical IR spectrum compared to PAR as shown previously ${ }^{35}$. Both spectra displayed bands at $\sim 1233$ and $1074 \mathrm{~cm}^{-1}$ corresponding to the anti-symmetric and symmetric phosphate vibrations, as well as bands at 1649 and $1605 \mathrm{~cm}^{-1}$, which correspond to the adenine moiety ${ }^{35,38}$. The main difference was observed at the band at $1695 \mathrm{~cm}^{-1}$, which is, therefore, indicative of the nicotinamide group. This was confirmed by the spectrum of nicotinamide mononucleotide (NMN), which also displayed a band at $1695 \mathrm{~cm}^{-1}$ (Fig. 3a).

To analyse the process of PARylation, PARP1 was allowed to bind to the immobilised DNA oligonucleotides, then $\mathrm{NAD}^{+}$was added, and immediately thereafter IR spectra were recorded for $80 \mathrm{~min}$ in 1-min intervals. First, we tested increasing concentrations of $\mathrm{NAD}^{+}$on PARP1 activity when bound to $\mathrm{DNA}_{\text {blunt }}$ (Fig. 3b). As expected, the spectrum of PARP1 remained nearly constant after adding buffer without $\mathrm{NAD}^{+}$. Slight decreases of the amide I and II bands were observed, presumably representing the diffusion of PARP1 from DNA into the supernatant. After adding $1 \mu \mathrm{M} \mathrm{NAD}{ }^{+}$, no major changes in the intensities of the amide I and II bands were observed either, but weak bands at 1236 and $1074 \mathrm{~cm}^{-1}$ were detected after $80 \mathrm{~min}$. These can be assigned to the phosphate vibrations of PAR, demonstrating that already at a concentration of $1 \mu \mathrm{M} \mathrm{NAD}^{+}$a weak modification of PARP1 takes place, which, however, did not result in the dissociation of PARP1 from the $\mathrm{DNA}_{\text {blunt }}$ oligonucleotide. The application of $10 \mu \mathrm{M} \mathrm{NAD}^{+}$led to a slight decrease of the amide I and II bands and at the same time a stronger increase of the PARderived phosphate vibration bands. This indicates that PARP1 was partly released from DNA, while at the same time PAR was formed. Both effects became stronger with increasing $\mathrm{NAD}^{+}$ concentrations. At a $\mathrm{NAD}^{+}$concentration of $500 \mu \mathrm{M}$, already after $\sim 10$ min the PARP1 signal disappeared almost completely. Comparison of the dissociation of PARP1 from DNA blunt at different $\mathrm{NAD}^{+}$concentrations indicate that higher $\mathrm{NAD}^{+}$ concentrations result in a more efficient dissociation of PARP1 from DNA (Fig. 3b, c). The calculated rate constants revealed that at higher $\mathrm{NAD}^{+}$concentrations not only the PARP1 dissociation became more efficient but this process was also significantly accelerated (Fig. 3c). Therefore, the catalytic turnover of $\mathrm{NAD}^{+}$ appears to be directly connected to the dissociation of PARP1

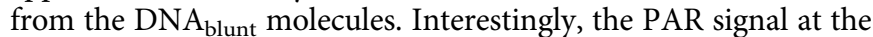
crystal surface increased over time, even though PARP1 was simultaneously released. This formation of PAR was more pronounced and faster at higher $\mathrm{NAD}^{+}$concentrations (Fig. 3d). 


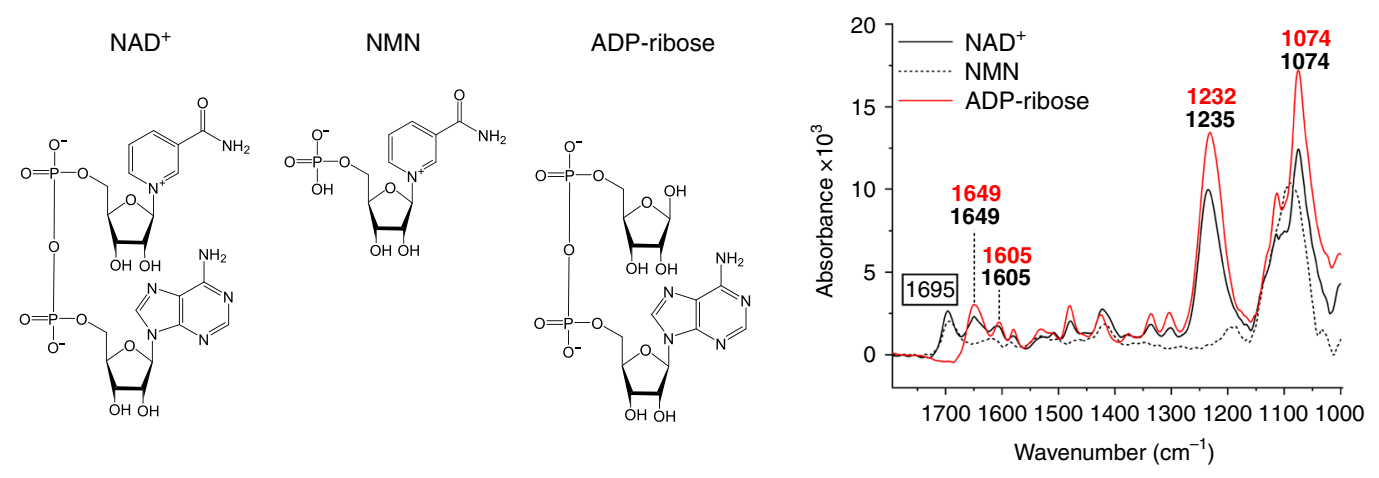

b
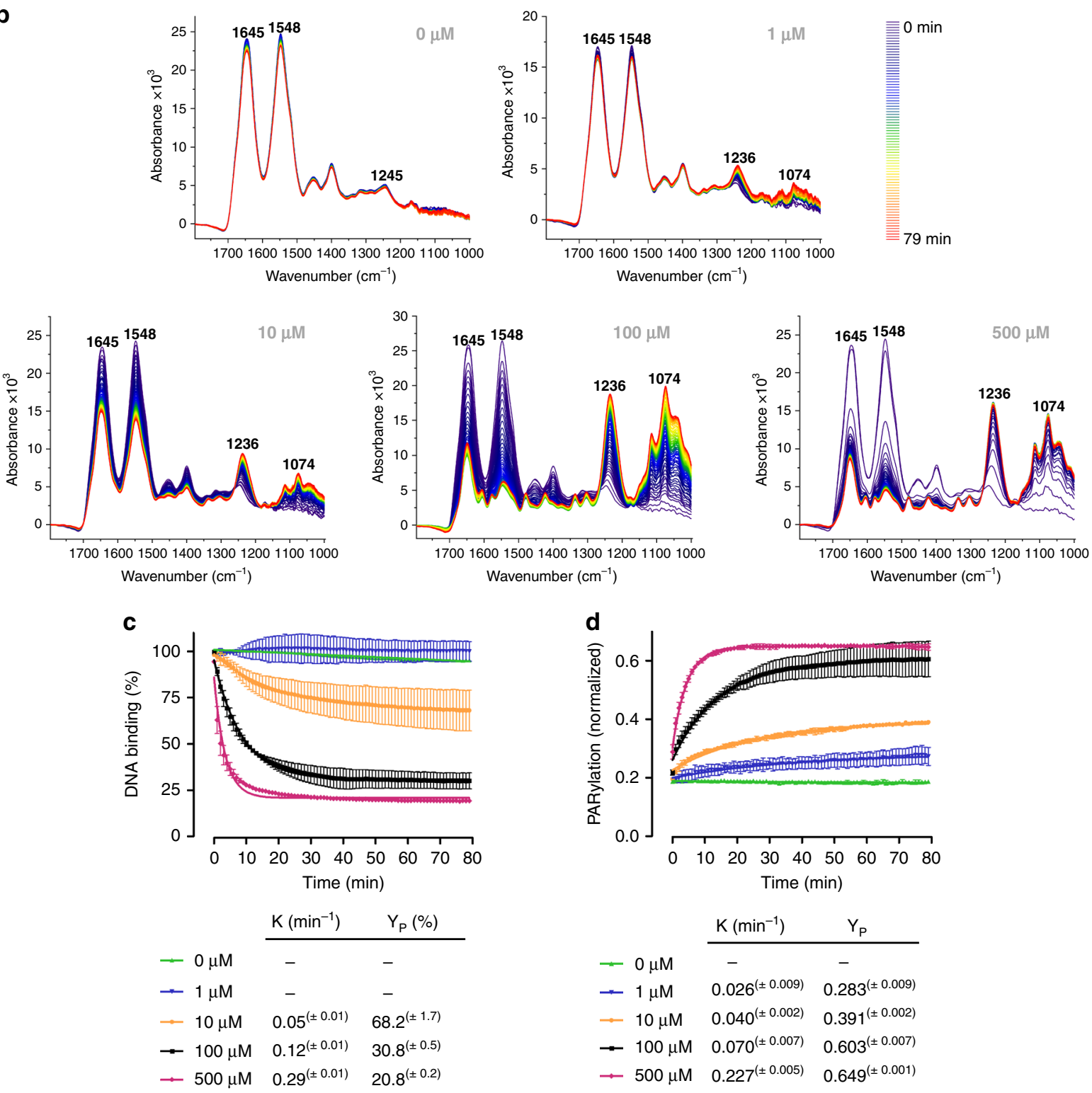

To test if this PAR signal was caused by residual DNA-bound auto-modified PARP1, the crystal surface was washed with $1 \mathrm{M}$ $\mathrm{NaCl}$ directly after the PARylation reaction to disrupt ionic interactions, and thereafter, with $1 \%$ SDS to disrupt non-covalent interactions (N.B. streptavidin-biotin interactions are not disrupted at this SDS concentration ${ }^{42,43}$ ). Washing with $1 \mathrm{M} \mathrm{NaCl}$ did not change the spectra significantly, suggesting that ionic interactions do not contribute primarily to the $\mathrm{DNA}_{\text {blunt }}-\mathrm{PARP} 1$

interactions (Supplementary Fig. 2a, c). Notably, under conditions without $\mathrm{NAD}^{+}$, more PARP1 could be removed by the high ionic strength buffer in comparison with conditions with $1 \mu \mathrm{M}$ $\mathrm{NAD}^{+}$. This suggests that already minor PARylation impacts the PARP1-DNA interaction. After washing with $1 \%$ SDS, most PARP1 was removed from the crystal, while the PAR signal was still detectable (Supplementary Fig. 2a, b). The ratio of the antisymmetric phosphate vibration $\left(1236 \mathrm{~cm}^{-1}\right)$ and the amide II 
Fig. 3 Real-time monitoring of PARP1-dependent PARylation at various NAD ${ }^{+}$concentrations. a Chemical structure and respective IR spectra of NAD ${ }^{+}$ NMN and ADP-ribose. The band assigned to the nicotinamide moiety $\left(1695 \mathrm{~cm}^{-1}\right)$ is indicated. $\mathbf{b}$ Representative time-dependent spectra following the addition of various $\mathrm{NAD}^{+}$concentrations to PARP1 bound to immobilised DNA blunt. Amide I $\left(1645 \mathrm{~cm}^{-1}\right)$ and amide II $\left(1548 \mathrm{~cm}^{-1}\right)$ bands of PARP1 and anti-symmetric $\left(1236 \mathrm{~cm}^{-1}\right)$ and symmetric $\left(1074 \mathrm{~cm}^{-1}\right)$ phosphate vibrations of generated PAR are indicated. $\mathbf{c}, \mathbf{d}$ Evaluation of $\mathbf{b}$. ' 0 min' refers to start of measurements. $\mathbf{c}$ Dissociation of PARP1 from DNA blunt upon addition of various NAD ${ }^{+}$concentrations. Time-dependent intensity decrease of the amide II band $\left(1548 \mathrm{~cm}^{-1}\right)$ was analysed. Intensity of the amide II band before addition of NAD+ was set to $100 \%$. PARP1 dissociation parameters were calculated via a mono-exponential fit function. $\mathbf{d}$ PAR formation upon addition of various $\mathrm{NAD}^{+}$concentrations. Time-dependent intensity increase of the antisymmetric phosphate vibration of PAR $\left(1236 \mathrm{~cm}^{-1}\right)$ was analysed. Data was normalised to the intensity of the amide II bands (1548 $\left.\mathrm{cm}^{-1}\right)$ of PARP1 before addition of $\mathrm{NAD}^{+}$. PAR formation parameters were calculated via a mono-exponential fit function. $\mathbf{c}$, $\mathbf{d}$ Data from same experiments. Means \pm SEM of $n=3$ $(100 \mu \mathrm{M})$ and $n=2(0,1,10$ and $500 \mu \mathrm{M})$ independent experiments, respectively. Source data are provided as a Source Data file.

band of PARP1 $\left(1548 \mathrm{~cm}^{-1}\right)$ can be used to estimate the PAR to protein ratio at the crystal surface. At higher $\mathrm{NAD}^{+}$concentrations, this ratio increased after washing with SDS buffer, suggesting that more PARP1 than PAR could be removed from the crystal surface (Supplementary Fig. 2d). These data imply that besides PARP1 itself, either DNA and/or streptavidin, which are immobilised at the crystal surface, became PARylated. As recently reported, covalent PARylation of DNA termini may represent one possible explanation for the PAR signal observed at the crystal surface ${ }^{44-47}$. In addition, streptavidin represents a potential PARylation target. This may occur, in a mechanism similar to the one recently demonstrated, showing that the substrate specificity of PARP1 is mainly determined by substrate proximity, which can lead to the PARylation of noncanonical substrates, such as GST ${ }^{48}$. Before addressing this issue again (see below), we analysed unbound PARP1 in the supernatant after completion of the PARylation reaction via western blotting to test the PARylation status of PARP1 released from the DNA oligonucleotides. Interestingly, the majority of PARP1 was strongly automodified (Supplementary Fig. 2e). In summary, the presence of $\mathrm{NAD}^{+}$as a PARP1 substrate led to a dose-dependent 'transPARylation' of molecules at the crystal surface, which correlated positively with the dissociation kinetics of PARP1 from DNA.

Next, we tested the impact of the type of DNA strand break structure on the PARylation process. After PARP1 bound to $\mathrm{DNA}_{3}{ }^{\prime} \mathrm{P}, \mathrm{DNA}_{5}$ 'P and $\mathrm{DNA}_{\text {nick}}$, PARylation was started by adding $100 \mu \mathrm{M} \mathrm{NAD}^{+}$. Depending on the individual DNA strand break model, significant differences were observed (Fig. 4a-c). Thus, PARP1 dissociated more efficiently from $\mathrm{DNA}_{3} \mathrm{P}$ and $\mathrm{DNA}_{\text {nick}}$, and less efficiently from $\mathrm{DNA}_{5}$ P compared to $\mathrm{DNA}_{\text {blunt }}$ (Fig. 4b). This correlated with a more pronounced PAR formation at $\mathrm{DNA}_{3}{ }^{\prime} \mathrm{P}$ and $\mathrm{DNA}_{\text {nick}}$, and a lower PAR formation at $\mathrm{DNA}_{5}{ }^{\prime} \mathrm{P}$ compared to $\mathrm{DNA}_{\text {blunt }}$ (Fig. 4c). The kinetics of PARP1 dissociation from DNA differed only moderately among the different DNA structures, but correlated with the kinetics of PAR formation (Fig. 4b, c). After washing with 1\% SDS, most PARP1 was removed from the crystal, whereas the PAR signal remained largely constant (Supplementary Fig. 3a-c). These data again suggest that the PAR signal detected did not derive from residual auto-modified PARP1 at the crystal surface, but from transPARylation of DNA or streptavidin. Therefore, we tested the potential trans-PARylation of streptavidin and/or DNA in gelbased assays. Notably, not DNA, but streptavidin was identified as a target for covalent modification (Fig. 4d; Supplementary Fig. $3 \mathrm{e}, \mathrm{f})$. In accordance with previous data ${ }^{48}$, this covalent modification was mediated by close proximity between PARP1 and streptavidin, which only occurred in the presence of biotinylated DNA and not in the presence of non-biotinylated DNA.

Next, we compared the ATR-FTIR spectroscopic findings on PARP1 activation by different DNA oligonucleotides with an orthogonal approach using a conventional gel-based assay in combination with TAMRA-labelled $\mathrm{NAD}^{+}$(Supplementary
Fig. 3d). In accordance with the IR spectroscopic findings, PARylation of PARP1 activated by DNA $_{5}$ 'P was significantly reduced. In contrast, we did not detect significant differences between PARylation of PARP1 activated by $\mathrm{DNA}_{\text {blunt }}, \mathrm{DNA}_{3}$ 'P and $\mathrm{DNA}_{\text {nick, }}$, probably due to a lack of sensitivity of the gel-based assay. Those data demonstrate the high sensitivity and reproducibility of the ATR-FTIR spectroscopic approach in comparison with conventional biochemical assays. In summary, these data provide strong evidence that streptavidin serves as a noncanonical PARylation substrate at the crystal surface, which can be efficiently used as a read-out for the analyses of PARP1 activity. Furthermore, these data demonstrate that PARylation by PARP1 is dependent on the type of DNA strand break structure affecting the dynamic and strongly interdependent processes of PARylation and PARP1 dissociation from DNA.

Structural changes of PARP1 upon PARylation. Several approaches demonstrated that PARP1 undergoes allosteric activation upon DNA binding, which is connected to structural distortions in the HD domain $14,22,27,28,41$. By using a nonhydrolysable $\mathrm{NAD}^{+}$analogue, recently first evidence was provided that $\mathrm{NAD}^{+}$binding to the catalytic centre might result in reverse allostery of PARP1 with regards to DNA binding ${ }^{27}$. The authors suggested that $\mathrm{NAD}^{+}$binding further shifts the $\mathrm{HD}$ to the unfolded conformation, which can then induce changes in the binding affinity for DNA lesions. However, due to the fast catalytic turnover of $\mathrm{NAD}^{+}$by PARP1, direct evidence supporting this hypothesis is still missing. Furthermore, it is still unknown, how PARylation affects the secondary structure of PARP1. To address these questions, we analysed structural changes of PARP1 during PARylation by reaction-induced difference spectroscopy. Therefore, we calculated difference spectra of PARP1 bound to the different DNA oligonucleotides, before and after the addition of $100 \mu \mathrm{M} \mathrm{NAD}{ }^{+}$(Fig. 5a; Supplementary Fig. 4a). All negative bands of the difference spectra represent structures that were more pronounced before the addition of $\mathrm{NAD}^{+}$, and all positive bands represent structures that were more pronounced after the addition of $\mathrm{NAD}^{+}$. The spectrum of PAR reveals two bands (1649 and $\left.1605 \mathrm{~cm}^{-1}\right)$ within the amide I region of PARP1 (1710-1595 $\mathrm{cm}^{-1}$ ) (Fig. 3a). Since during PARylation the PARP1 signal decreased and the overlapping PAR signal increased, we limited the structural analysis to the first $2 \mathrm{~min}$. Spectral characteristics of PARP1 were found to be comparable for all DNA oligonucleotides, indicating that structural changes of PARP1 are independent of the type of DNA strand break. Two minutes after $\mathrm{NAD}^{+}$ addition, distinct positive bands at $\sim 1655 \mathrm{~cm}^{-1}$ and $\sim 1605 \mathrm{~cm}^{-1}$ were detected, which can be assigned to the overlapping PAR bands. This implies that already at very early time points of the PARylation reaction difference spectra are dominated by the arising PAR chains. To compensate the decrease of the PARP1 signal due to dissociation during PARylation, all amide I bands were normalised before calculating difference spectra. The formation of PAR, however, resulted in additional absorbance in 


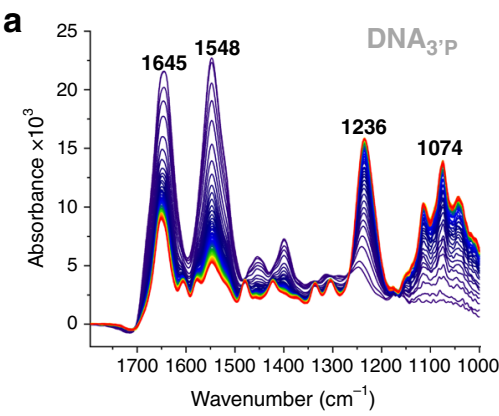

b

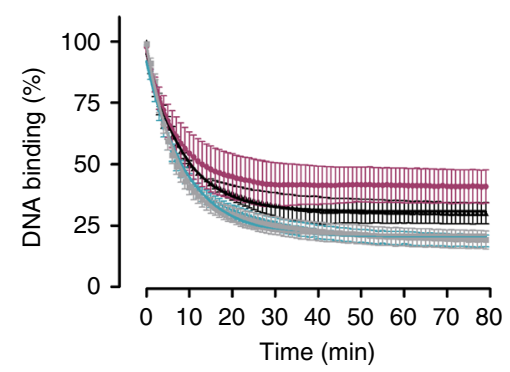

\begin{tabular}{lll} 
& $K\left(\min ^{-1}\right)$ & $Y_{P}(\%)$ \\
\cline { 2 - 3 } - DNA $_{\text {blunt }}$ & $0.117^{( \pm 0.007)}$ & $30.8^{( \pm 0.5)}$ \\
- DNA $_{3^{\prime} P}$ & $0.107^{( \pm 0.004)}$ & $20.6^{( \pm 0.4)}$ \\
- DNA $_{5^{\prime} P}$ & $0.144^{( \pm 0.019)}$ & $41.4^{( \pm 0.9)}$ \\
- DNA $_{\text {nick }}$ & $0.128^{( \pm 0.006)}$ & $21.3^{( \pm 0.4)}$
\end{tabular}
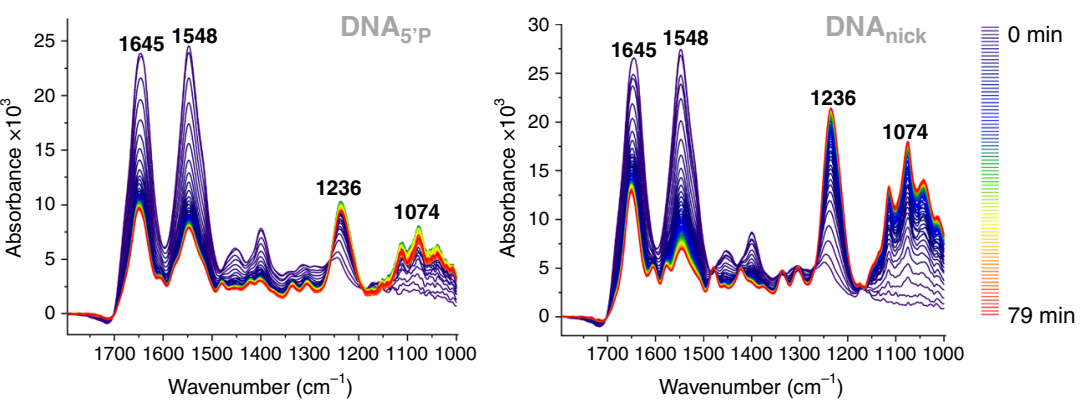

C

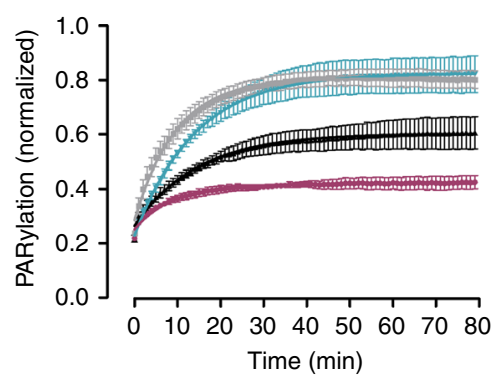

\begin{tabular}{llc} 
& $K\left(\mathrm{~min}^{-1}\right)$ & $Y_{\mathrm{P}}$ \\
\cline { 2 - 3 }$=$ DNA $_{\text {blunt }}$ & $0.07^{( \pm 0.007)}$ & $0.60^{( \pm 0.007)}$ \\
- DNA $_{3^{\prime} \mathrm{P}}$ & $0.07^{( \pm 0.005)}$ & $0.83^{( \pm 0.008)}$ \\
- DNA $_{5^{\prime} \mathrm{P}}$ & $0.11^{( \pm 0.010)}$ & $0.42^{( \pm 0.002)}$ \\
- DNA $_{\text {nick }}$ & $0.10^{( \pm 0.005)}$ & $0.81^{( \pm 0.004)}$
\end{tabular} d

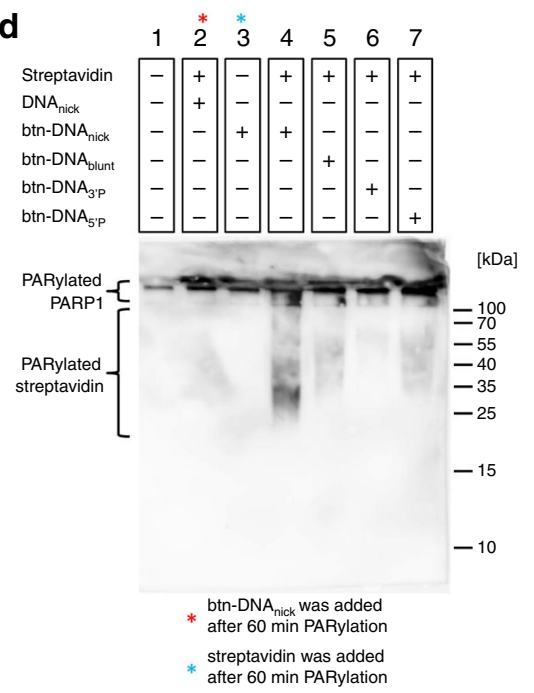

Fig. 4 Real-time monitoring of PARP1-dependent PARylation at various DNA strand break models. a Representative time-dependent spectra following the addition of $100 \mu \mathrm{M} \mathrm{NAD}^{+}$to PARP1 bound to immobilised DNA ${ }_{3^{\prime} \mathrm{P}}, \mathrm{DNA}_{5^{\prime} \mathrm{P}}$ or DNA $\mathrm{A}_{\text {nick. }}$. Amide I $\left(1645 \mathrm{~cm}^{-1}\right)$ and amide II $\left(1548 \mathrm{~cm}^{-1}\right)$ bands of PARP1 and anti-symmetric $\left(1236 \mathrm{~cm}^{-1}\right)$ and symmetric $\left(1074 \mathrm{~cm}^{-1}\right)$ phosphate vibrations of generated PAR are indicated. b, $\mathbf{c}$ Evaluation of a. ' 0 min' refers to start of measurements. $\mathbf{b}$ Dissociation of PARP1 from $D N A_{\text {blunt, }} D N A_{3^{\prime} P}, D N A_{5^{\prime} P}$ or $D N A_{\text {nick }}$ upon addition of NAD ${ }^{+}$. Time-dependent intensity decrease of the amide II band $\left(1548 \mathrm{~cm}^{-1}\right)$ was analysed. Intensity of the amide II band before addition of $\mathrm{NAD}^{+}$was set to 100\%. PARP1 dissociation parameters were calculated via a mono-exponential fit function. c PAR formation upon addition of NAD ${ }^{+}$. Time-dependent intensity increase of the anti-symmetric phosphate vibration of PAR $\left(1236 \mathrm{~cm}^{-1}\right)$ was analysed. Data were normalised to the intensity of the amide II bands $\left(1548 \mathrm{~cm}^{-1}\right)$ of PARP1 before addition of $\mathrm{NAD}^{+}$. PAR formation parameters were calculated via a mono-exponential fit function. $\mathbf{b}, \mathbf{c}$ Data from same experiments. Means \pm SEM of $n=3$ independent experiments. $\mathbf{d}$ Analysis of covalent PARylation of streptavidin in the presence of biotinylated (btn-DNA) and non-biotinylated DNA (DNA) via western blot and subsequent immunodetection of PAR. PARP1 $(1 \mu \mathrm{M})$ and NAD+ $(500 \mu \mathrm{M})$ were present in all samples. Immunodetection of PARP1 is shown in Supplementary Fig. 3e. Source data are provided as a Source Data file.

the amide I region, which could not be considered in the normalisation procedure. Consequently, all positive difference bands arising from PAR within the difference spectra also resulted in negative difference bands. Those bands were therefore excluded from secondary structure predictions. Despite the strong impact of PAR on the difference spectra, we detected a positive band at $1639-1642 \mathrm{~cm}^{-1}$ directly after the addition of NAD ${ }^{+}$(Fig. 5a; Supplementary Fig. 4a). This band position is neither typical for $\mathrm{PAR}$ nor for $\mathrm{NAD}^{+}$, and is therefore indicative for changes in the PARP1 secondary structure. Isotopic labelling of molecules offers a possibility to induce distinct frequency shifts of infrared absorption bands. By introducing isotopic labels into $\mathrm{NAD}^{+}$, we aimed to shift the bands at 1649 and $1605 \mathrm{~cm}^{-1}$, which overlap the amide I region, to lower frequencies, thereby improving structural analysis of PARP1 during PARylation. We synthesised isotopically labelled $\mathrm{NAD}^{+}$enzymatically using ${ }^{13} \mathrm{C},{ }^{15} \mathrm{~N}-\mathrm{ATP}$. First, we analysed the infrared spectrum of ${ }^{13} \mathrm{C},{ }^{15} \mathrm{~N}-\mathrm{ATP}$ and compared it to the spectrum of unlabelled ATP (Fig. 5b). As expected, the infrared absorption bands of ATP at 1650 and 1604 $\mathrm{cm}^{-1}$ were shifted to lower frequencies by the introduced isotopic labels. One band at $1624 \mathrm{~cm}^{-1}$ remained within the amide I region. Yet, an improved analysis of structural changes of PARP1 was expected. The enzymatic synthesis of isotopically labelled $\mathrm{NAD}^{+}$was performed using nicotinamide nucleotide adenylyltransferase 1 (NMNAT1), which uses ATP and NMN as substrates, while releasing pyrophosphate as a by-product. To shift the equilibrium of the reaction towards the production of $\mathrm{NAD}^{+}$, we added pyrophosphatase (PPase), which cleaves the pyrophosphate produced (Fig. 5c). This approach resulted in an almost complete conversion of ${ }^{13} \mathrm{C},{ }^{15} \mathrm{~N}-\mathrm{ATP}$ and $\mathrm{NMN}$ to ${ }^{13} \mathrm{C},{ }^{15} \mathrm{~N}-\mathrm{NAD}$ + (Supplementary Fig. 4b). Next, we analysed PARylation by the addition of $100 \mu \mathrm{M}^{13} \mathrm{C},{ }^{15} \mathrm{~N}-\mathrm{NAD}^{+}$to PARP1 bound to immobilised $\mathrm{DNA}_{\text {blunt }}$. As expected, the PARylation reaction was not affected by the isotopic label (Supplementary Fig. 4c). Amide I and II bands decreased rapidly, while distinct bands at 1233 and $1078 \mathrm{~cm}^{-1}$ arose, which represent the slightly shifted phosphate vibrations. Calculated difference spectra revealed a clear positive band at $1622 \mathrm{~cm}^{-1}$ after 2 min (Fig. 5d; Supplementary Fig. 4d). This band can be assigned to isotopically labelled PAR, which displays similar infrared absorption bands like isotopically 
a
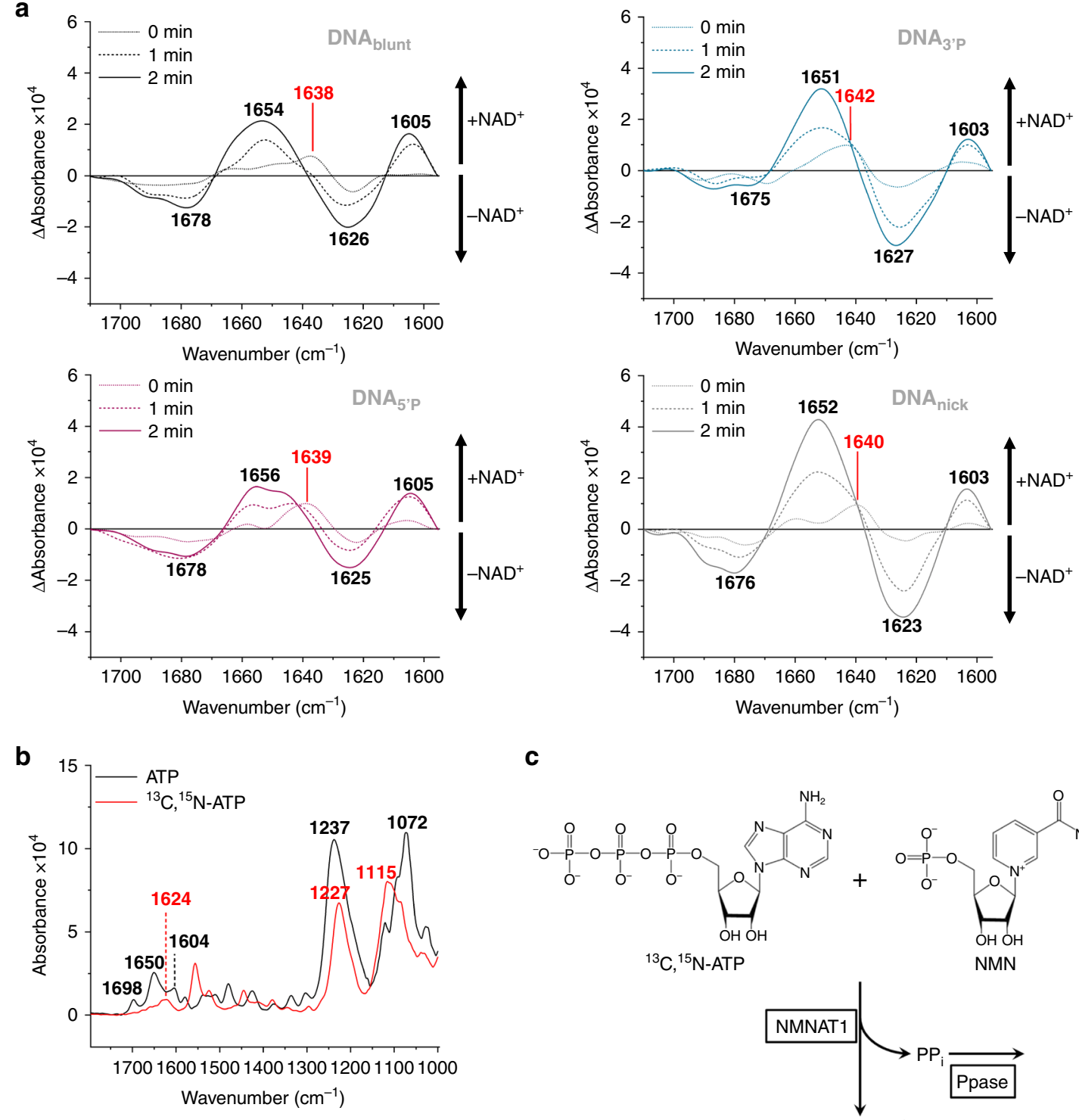

C

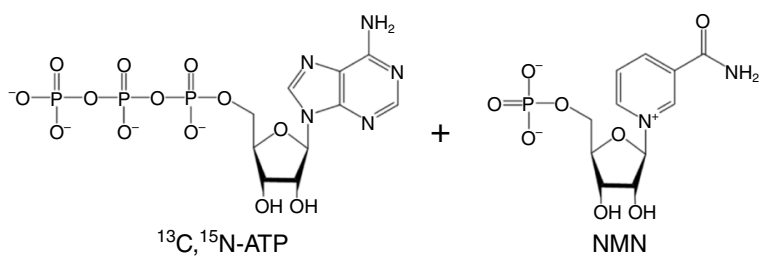
${ }^{13} \mathrm{C},{ }^{15} \mathrm{~N}-\mathrm{ATP}$
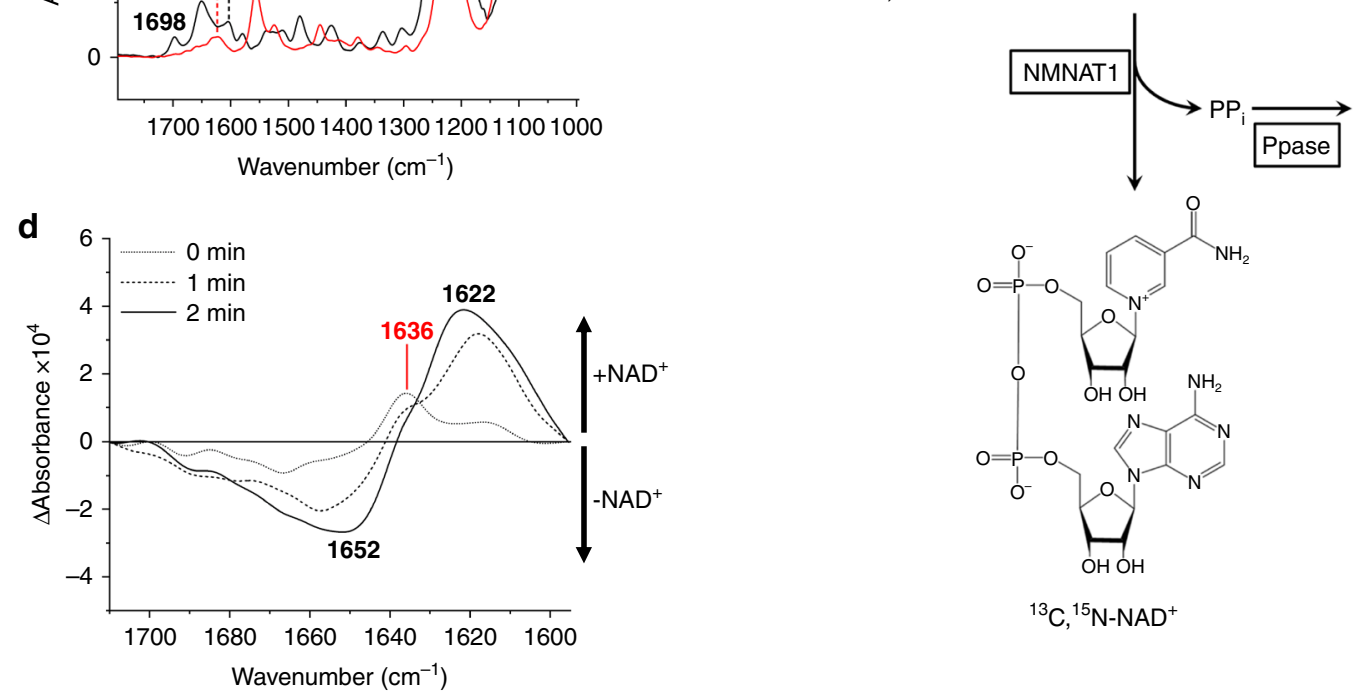

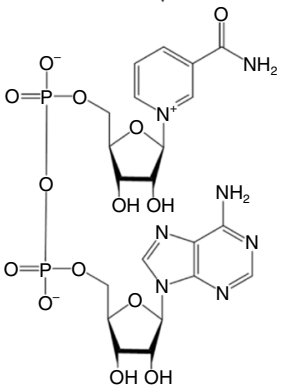

${ }^{13} \mathrm{C},{ }^{15} \mathrm{~N}-\mathrm{NAD}+$

Fig. 5 Secondary structure analysis of PARP1 upon NAD ${ }^{+}$addition. a Comparison of PARP1 bound to immobilised DNA $A_{b l u n t}, D^{\prime} A_{3^{\prime} P}, D^{\prime} A_{5^{\prime} P}$ or $D N A_{\text {nick. }}$ Difference spectra of amide I bands of PARP1 before and after the addition of $100 \mu \mathrm{MNAD}+(0,1$ and 2 min) were calculated. Average curves of $n=3$ independent experiments are plotted, respectively. SDs are shown in Supplementary Fig. 4a. Positive difference bands distinct from PAR bands are indicated in red. b Spectra of unlabelled and isotopically labelled ${ }^{13} \mathrm{C},{ }^{15} \mathrm{~N}-\mathrm{ATP}$. c Strategy for the enzymatic synthesis of isotopically labelled ${ }^{13} \mathrm{C},{ }^{15} \mathrm{~N}-\mathrm{NAD}+$. d Difference spectra of amide I bands of PARP1 bound to DNA blunt before and after the addition of $100 \mu M^{13} C_{,}^{15} \mathrm{~N}-N_{A} D^{+}(0,1$ and 2 min) were calculated. Average curves of $n=3$ independent experiments are plotted. SDs are shown in Supplementary Fig. 4d. The positive difference band distinct from the PAR band is indicated in red. Source data are provided as a Source Data file. 
labelled ATP (Fig. 5b). Strikingly, directly after the addition of ${ }^{13} \mathrm{C},{ }^{15} \mathrm{~N}-\mathrm{NAD}^{+}$, a distinct positive band at $1636 \mathrm{~cm}^{-1}$ was resolved similar to the one observed after the addition of unlabelled NAD ${ }^{+}$(Fig. 5d; Supplementary Fig. 4d). Since this effect was independent of the $\mathrm{NAD}^{+}$substrate, these data provide strong evidence for structural changes of PARP1 itself. The position of the band at $1636-1642 \mathrm{~cm}^{-1}$ can be assigned to disordered or $\beta$-sheet structures suggesting that the proportion of those structures increases after addition of $\mathrm{NAD}^{+49}$. Mainly two processes could cause these structural changes: $\mathrm{NAD}^{+}$binding or PARylation of PARP1 itself, which, at this level, did not result in its dissociation from DNA. To test the second hypothesis, we performed spectral analysis of PARP1 during PARylation at various $\mathrm{NAD}^{+}$concentrations (Supplementary Fig. 5). Low concentrations of $\mathrm{NAD}^{+}$, which resulted in only slight PARylation, did not reveal significant structural changes of PARP1, even after $60 \mathrm{~min}$. In contrast, directly after the addition of $500 \mu \mathrm{M}$ $\mathrm{NAD}^{+}$a clear positive difference band at $1640 \mathrm{~cm}^{-1}$ could be resolved. These observations suggest that the structural changes are caused by binding of $\mathrm{NAD}^{+}$to the catalytic centre, which were only resolved at high $\mathrm{NAD}^{+}$concentrations, when binding occurred simultaneously at most PARP1 molecules.

To investigate the effect of $\mathrm{NAD}^{+}$binding in more detail, we studied the PARP1 variant PARP1 ${ }^{\mathrm{E} 988 \mathrm{~K}}$. The residue E988 is highly conserved among PARPs, and is part of the catalytic triad within the donor site ${ }^{50}$. Mutations of this residue were shown to result in MARylation activity only ${ }^{51-54}$. Accordingly, only elongation, but not $\mathrm{NAD}^{+}$binding, seems to be affected by these mutations. First, we analysed the activity of PARP1 ${ }^{\mathrm{E} 988 \mathrm{~K}}$ in a gelbased assay using TAMRA-labelled $\mathrm{NAD}^{+}$(Supplementary Fig. 6a). This analysis confirmed the MARylation activity of PARP1 ${ }^{\mathrm{E} 988 \mathrm{~K}}$. Thus, instead of an upwards shift of PARP1 ${ }^{\mathrm{E} 988 \mathrm{~K}}$ in the gel, which is caused by PARP1 automodification with long PAR chains, a clear increase of the intensity of the PARP1 ${ }^{\mathrm{E} 988 \mathrm{~K}}$ band was evident, indicating automodification with monomers. Next, we tested the DNA-binding properties of PARP1 ${ }^{\mathrm{E} 988 \mathrm{~K}}$ via ATR-FTIR spectroscopy. Therefore, we immobilised $\mathrm{DNA}_{\text {blunt }}$ at the crystal surface, added PARP1 ${ }^{\mathrm{E} 988 \mathrm{~K}}$ and monitored binding over time (Supplementary Fig. 6b). PARP1 $1^{\mathrm{E} 988 \mathrm{~K}}$ signal intensities increased rapidly and reached saturation $\sim 10$ min after addition, which is comparable with wild-type PARP1. Interestingly, binding of PARP1 ${ }^{\mathrm{E} 988 \mathrm{~K}}\left(0.52 \mathrm{~min}^{-1}\right)$ was slightly faster compared to wild-type PARP1 $\left(0.41 \mathrm{~min}^{-1}\right)$. Yet, the total amount of PARP1 ${ }^{\mathrm{E} 988 \mathrm{~K}}$, which was bound to $\mathrm{DNA}_{\text {blunt, }}$ was $25 \%$ less (Supplementary Fig. 6c). So far, no structural information about PARP1 E988 mutants exist. We calculated difference spectra to compare secondary structures of wild-type PARP1 and PAR$\mathrm{P}^{\mathrm{E} 988 \mathrm{~K}}$ when bound to $\mathrm{DNA}_{\text {blunt }}$. Interestingly, distinct positive and negative bands were resolved, indicating distinct structural differences between both variants (Supplementary Fig. 6d). Two positive difference bands at 1660 and $1637 \mathrm{~cm}^{-1}$ were resolved representing structural components, which were more frequent in PARP1 ${ }^{\text {E988K }}$. The band at $1660 \mathrm{~cm}^{-1}$ is indicative for a-helices, $\beta$-turns or $33_{10}$-helices, while the band at $1637 \mathrm{~cm}^{-1}$ is indicative of $\beta$-sheet structures ${ }^{49,55}$. In addition, one major negative band at $1612 \mathrm{~cm}^{-1}$ was resolved, representing structural components, which were more frequent in wild-type PARP1. The positions of this band can also be assigned to $\beta$-sheet structures ${ }^{49,55}$. A position at lower frequencies can be the result of stronger hydrogen bonds and an increase in the number of $\beta$ strands ${ }^{49,56,57}$. In turn, this suggests that the introduced mutation results in the loss of compact or extended $\beta$-sheet structures. Considering that the residue E988 is part of a $\beta$-sheet structure within the catalytic domain, these results suggest a destabilising effect of the catalytic domain caused by the introduced mutation.
Next, we tested the effect of $\mathrm{NAD}^{+}$addition on the structure of the PARP1 ${ }^{\text {E988K }}$ mutant (Supplementary Fig. 6e). Neither PAR formation nor PARP1 release was observed, confirming the loss of PARylation activity and trapping of PARP1 molecules at the DNA oligonucleotides. Similarly to wild-type PARP1, distinct structural changes were also observed for PARP1 ${ }^{\mathrm{E} 988 \mathrm{~K}}$ upon addition of $\mathrm{NAD}^{+}$(Supplementary Fig. 6f). Of note, difference spectra, which are much more sensitive than absorbance spectra, did not reveal PAR signals after $\mathrm{NAD}^{+}$addition, indicating a complete absence of PAR formation. Directly after $\mathrm{NAD}^{+}$ addition, one major positive difference band at $1649 \mathrm{~cm}^{-1}$ was resolved. It represents structures, which were more frequent after $\mathrm{NAD}^{+}$addition and can be assigned to $\alpha$-helices or disordered structures ${ }^{49,55}$. Those structural changes were only resolved directly after $\mathrm{NAD}^{+}$addition, and are therefore very likely caused by $\mathrm{NAD}^{+}$binding rather than by MARylation. Notably, this positive difference band was close to the position of the positive difference band observed for PARP1 after $\mathrm{NAD}^{+}$addition $\left(1639-1642 \mathrm{~cm}^{-1}\right)$. As the complete spectral region can be assigned to disordered structures, those data provide further evidence for a shift of the HD to the unfolded conformation upon $\mathrm{NAD}^{+}$binding, which has been postulated before ${ }^{27}$. As the structure of PARP1 ${ }^{\mathrm{E} 988 \mathrm{~K}}$ was significantly affected by the introduced mutation (Supplementary Fig. 6d), it is very likely that the $\mathrm{NAD}^{+}$-binding mechanism and structural consequences thereof were also affected, which may explain why the exact positions of the difference bands were not identical for PARP1 1 WT and PARP $1^{\mathrm{E} 988 \mathrm{~K}}$. In summary, we provide evidence for distinct changes in the secondary structure of PARP1 upon binding to $\mathrm{NAD}^{+}$, suggesting the formation of disordered or $\beta$-sheet structures.

Structural changes of PARP1 upon inhibitor binding. The mechanism of reverse allostery of PARP1 with regards to its DNA-binding affinity has not only been proposed for $\mathrm{NAD}^{+}$ binding but also for the binding of PARP inhibitors $9,58,59$. Such allosteric conformational changes were expected to stabilise DNA binding of PARP1 and could thereby explain the so called 'trapping' mechanism ${ }^{58,59}$, which is considered to be responsible for the clinical efficacy of PARP inhibitors. To analyse the proposed allosteric binding, we added veliparib and olaparib to $D_{N A} A_{\text {blunt }}$-bound PARP1 and performed a secondary structure analysis. We calculated difference spectra of PARP1 in the presence or absence of inhibitors (Fig. 6a, b). Positive difference bands represent structural components of the inhibitor-bound state, and negative difference bands represent structural components of the unbound state. Interestingly, binding of veliparib and olaparib resulted in a positive band at $\sim 1639 \mathrm{~cm}^{-1}$. The position of the band was similar to the one observed after addition of $\mathrm{NAD}^{+}$(Fig. 5a, d) and can be assigned to disordered or $\beta$-sheet structures ${ }^{49}$. This finding points to a common binding mechanism with similar structural consequences for PARP1. Moreover, a negative band was observed in the region $1620-1625 \mathrm{~cm}^{-1}$, which can be assigned to $\beta$-sheet structures as well ${ }^{49}$. In contrast to the position at $\sim 1639 \mathrm{~cm}^{-1}$, the position at $1620-1625 \mathrm{~cm}^{-1}$ is more representative for extended $\beta$-sheet structures with stronger hydrogen bonds ${ }^{49,56,57}$. This suggests a loss of this type of $\beta$-sheet structures upon binding to PARP inhibitors. Next, we tested the inhibitory effect of both inhibitors by adding $100 \mu \mathrm{M} \mathrm{NAD}^{+}$. The presence of veliparib or olaparib completely suppressed the formation of PAR and thereby the dissociation of PARP1 from DNA (Fig. 6c; Supplementary Fig. 7a, b). Importantly, difference spectra did not reveal significant structural changes of PARP1 upon $\mathrm{NAD}^{+}$addition after preincubation with inhibitors (Supplementary Fig. 7a, b). This demonstrates the specificity of the 
a

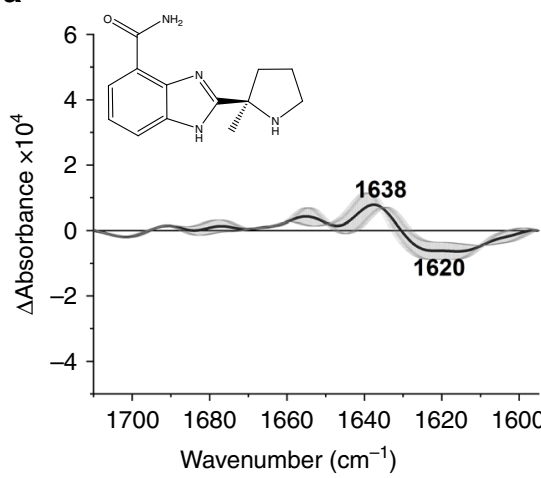

C

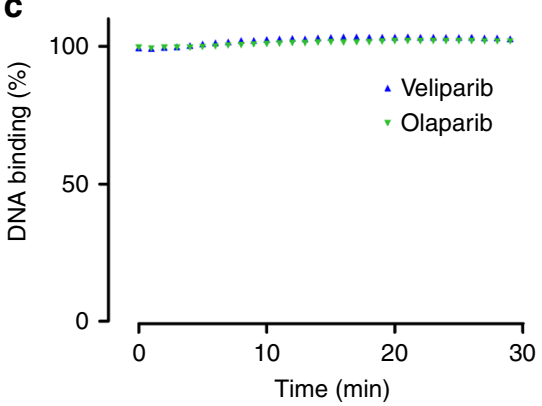

b

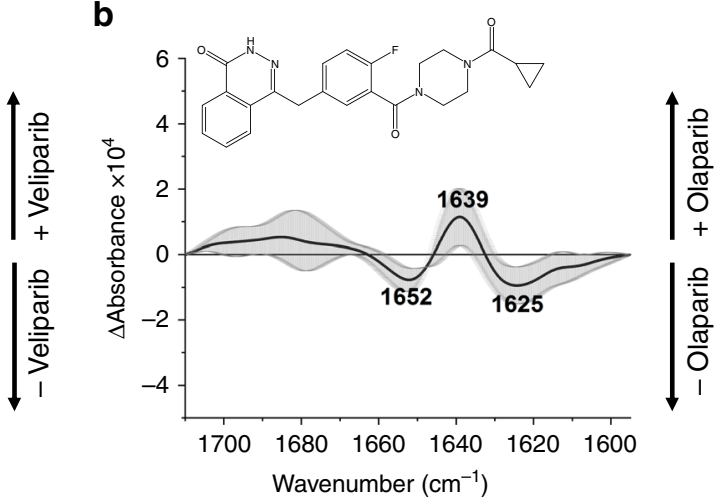

d

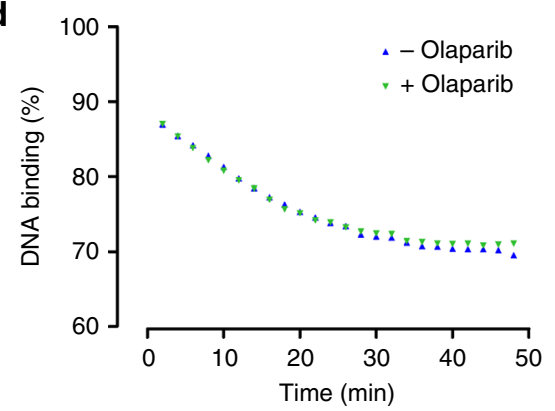

Fig. 6 Effect of inhibitor binding on PARP1 structure and DNA binding properties. a Secondary structure analysis of PARP1 upon binding to veliparib.

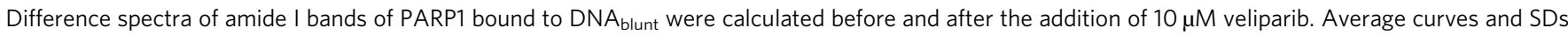
(grey) of two experiments are plotted. $\mathbf{b}$ Secondary structure analysis of PARP1 upon binding to olaparib. Difference spectra of amide I bands of PARP1 bound to DNA blunt before and after the addition of $10 \mu \mathrm{M}$ veliparib were calculated. Average curves and SDs (grey) of two experiments are plotted. c Evaluation of inhibitory effect of veliparib and olaparib. Dissociation of PARP1 from DNA blunt upon addition of $100 \mu M$ NAD + in the presence of inhibitor was tested. Time-dependent intensity decrease of the amide II band $\left(1548 \mathrm{~cm}^{-1}\right)$ was analysed. Intensity of the amide II band before addition of NAD+ was set to $100 \%$. d Analysis of 'trapping' effect of olaparib. Binding of PARP1 to immobilised DNA $A_{\text {blunt }}$ was competed by the addition of free DNA $A_{\text {blunt }}$ in the supernatant in the absence or in the presence of olaparib. Time-dependent intensity decrease of the amide I band $\left(1645 \mathrm{~cm}^{-1}\right)$ was analysed. Intensity of the amide I band before addition of free $D N A_{\text {blunt }}$ was set to $100 \%$. Source data are provided as a Source Data file.

observed structural changes of PARP1 after binding of molecules to the catalytic cleft. As the mechanism of allosteric binding was proposed to stabilise DNA binding, we tested the effect of inhi-

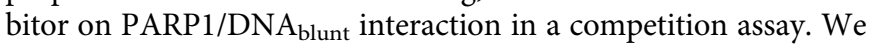
focused our analysis to olaparib, as the trapping effect was shown to be stronger for this inhibitor ${ }^{9}$. PARP1 was bound to immobilised $\mathrm{DNA}_{\text {blunt }}$, and free $\mathrm{DNA}_{\text {blunt }}$ was added in the supernatant in the absence or presence of olaparib. The signal of PARP1 decreased independent of the presence of olaparib (Fig. 6d). This indicates that olaparib did not stabilise PARP1 on immobilised $\mathrm{DNA}_{\text {blunt }}$, but allowed an exchange of PARP1 to the free $\mathrm{DNA}_{\text {blunt }}$ in the supernatant. Similar results have been obtained in previous studies by applying a series of biochemical methods ${ }^{1,60}$. In summary, binding of veliparib and olaparib to PARP1 result in structural changes of PARP1, which are similar to those of $\mathrm{NAD}^{+}$binding. Binding did not lead to stronger DNA-binding affinity, yet was able to trap PARP1 on DNA.

\section{Discussion}

In this study, we investigated the molecular dynamics of DNAdependent, PARP1-mediated PARylation in real time by direct recording of ATR-FTIR spectroscopic data (Fig. 7). While binding and activation by PARP1 showed similar kinetics at four different DNA strand break structures, distinct differences were revealed for the PARylation reaction itself, as well as for the dissociation of PARP1 from the different DNA molecules. A strong PAR formation correlated with an efficient dissociation of PARP1 from DNA demonstrating the interdependence of both processes. Interestingly, the strongest PAR formation and most efficient dissociation were observed at single nicks $\left(\mathrm{DNA}_{\text {nick }}\right)$ and $3^{\prime}$ phosphorylated ends $\left(\mathrm{DNA}_{3^{\prime} \mathrm{P}}\right)$. The strong activation at single nicks is consistent with the fact that PARP1 is of critical importance for the rapid and efficient repair of single-strand breaks ${ }^{2,61,62}$. Considering PARP1's general role in DNA repair, the preferred activation of PARP1 at $3^{\prime}$ phosphorylated ends is not unexpected either. $3^{\prime}$ phosphorylated ends are nonphysiological and occur frequently during genotoxic insults in cells. Besides the direct induction via ionising irradiation they can occur after topoisomerase 1 inhibition or during base excision repair $^{63}$. Accordingly, we observed a weaker activation of PARP1 at $5^{\prime}$ phosphorylated DNA ends, which mainly occur under physiological conditions during DNA replication. Therefore, our data support PARP1's central role in the DNA damage response. Interestingly, PARP2 and PARP3 are mainly active at $5^{\prime}$ phosphorylated ends ${ }^{8}$, suggesting specific roles for the DNAdependent PARPs in cells. Nevertheless, the fact that PARP1 was active at all tested DNA strand break structures and that differences in PARylation activities at the different DNA oligonucleotides were less than twofold is consistent with an assumed redundancy between PARP1 and PARP2 ${ }^{64}$. While each of them might have preferential DNA structures for activation, and thereby fulfil unique roles in cellular processes, losing one of them can at least partly be compensated by the other. It is worth mentioning that recent data analysing the activation of PARP1 at various types of DNA strand breaks via a colorimetric assay did not result in significant differences in PAR formation ${ }^{8}$. Still, there was a trend of preferred activation of PARP1 at $3^{\prime}$ phosphorylated 


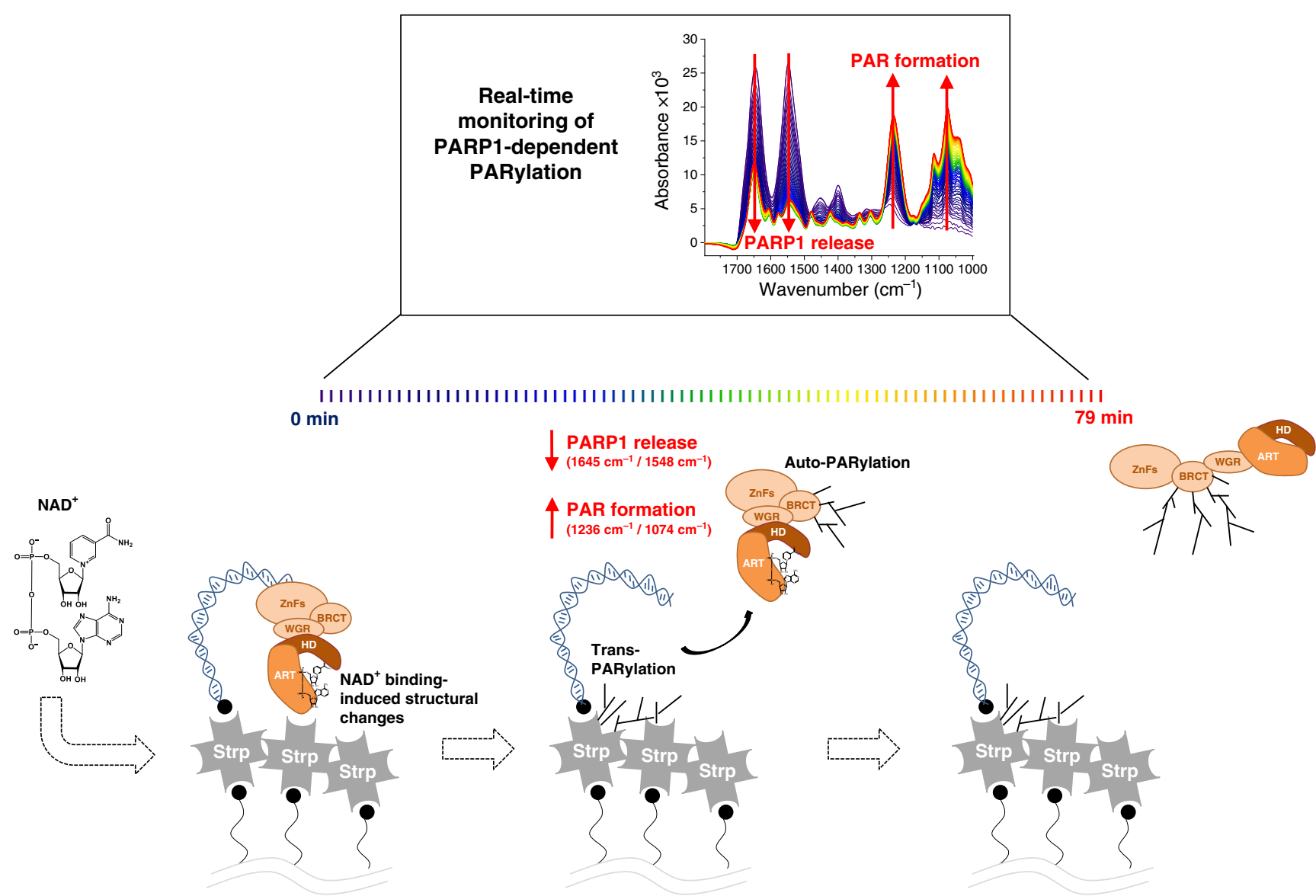

Fig. 7 Mechanistic model of PARP1-dependent PARylation derived by time-resolved ATR-FTIR spectroscopy. Directly after NAD ${ }^{+}$addition binding of $\mathrm{NAD}^{+}$to the catalytic centre induces distinct structural changes of PARP1. This is followed by the release of PARP1 from DNA, which is reflected by a decrease of PARP1 signal intensity (amide I $\left(1645 \mathrm{~cm}^{-1}\right)$ and amide II $\left(1548 \mathrm{~cm}^{-1}\right)$ bands), and the simultaneous formation of PAR, which is reflected by an increase of PAR signal intensities [anti-symmetric $\left(1236 \mathrm{~cm}^{-1}\right)$ and symmetric $\left(1074 \mathrm{~cm}^{-1}\right)$ phosphate vibrations]. The observed formation of PAR is mainly due to trans-PARylation of streptavidin, which is mediated by the close proximity of streptavidin to the DNA strand break.

ends, which demonstrates the high sensitivity and reproducibility of the IR spectroscopic approach in comparison with conventional methods. While most methods detect PAR formation only indirectly (e.g. via antibodies or streptavidin-biotin interaction), the ATR-FTIR spectroscopic approach enables direct and labelfree monitoring of the enzymatic reaction, thus improving sensitivity, reproducibility and time-resolved analyses.

After adding $\mathrm{NAD}^{+}$, we observed a decrease of PARP1 signal indicating the dissociation of PARP1 from DNA due to PARylation. It is generally assumed that automodification of PARP1 results in steric and electrostatic repulsion and thereby the release of PARP1 from DNA ${ }^{8,11}$. Yet, the exact mechanism is still not completely understood. Our approach allows to study the interplay of PARP1-mediated PARylation and its dissociation from DNA in real time. Remarkably, along with PARP1's dissociation, we observed an increase of PAR signal at the crystal surface, which persisted after removal of PARP1 and which is caused by the covalent modification of streptavidin. Even though streptavidin is not a bona fide target of PARP1, the proximity between PARP1 and streptavidin in our setup apparently allows covalent modification, in an analogous way as shown for GST ${ }^{48}$. Considering DNA damage-dependent PARylation in cells, a similar mechanism of trans-PARylation might explain the observed modification of histones $2,5,65$.

The strong positive correlation of PAR formation and PARP1 dissociation suggests that the trans-PARylation supports PARP1 dissociation. Yet, since kinetics of dissociation were faster than kinetics of PAR formation, it is likely that automodification also contributes to the dissociation process. If automodification of PARP1 mediates its dissociation from DNA, we would expect a fast increase of the PAR signal, which decreases along with the dissociation of auto-modified PARP1. However, a decrease of PAR signal was not observed at any time. This might be caused by limited detectability, because the trans-PARylation at the crystal surface overlays the decrease of the PAR signal, due to the release of auto-modified PARP1. Still, the absence of a detectable decrease of the PAR signal suggests that there is no strong automodification of PARP1 occurring at the crystal surface. Therefore, it can be assumed that already weak automodification of PARP1 mediates an efficient release from DNA. This is in line with findings that PARP3 can dissociate from DNA even though it produces only very short chains ${ }^{8}$. Notably, as we detected strong automodification of PARP1 after its release from the crystal surface, but not or only to a minor extent at the crystal surface, this leaves room for speculation that PARP1 automodification mainly occurs after its initial activation in the absence of DNA.

Activation of PARP1 upon DNA binding can be explained by an allosteric binding mechanism resulting in the partial unfolding of the HD domain and thereby accessibility of $\mathrm{NAD}^{+}$to the active site. In contrast, structural consequences of $\mathrm{NAD}^{+}$binding and PARP1 automodification are less well understood, mainly due to the dynamic and complex interdependencies of these processes. By studying PARP1-dependent PARylation in real 
time, we uncovered structural changes of full-length PARP1 upon addition of $\mathrm{NAD}^{+}$. The observed positive difference band between $1636-1642 \mathrm{~cm}^{-1}$ can be assigned to an increase of disordered or $\beta$-sheet structures. As those structural changes were only observed directly after addition of $\mathrm{NAD}^{+}$, in the absence of significant PAR signal and only at high $\mathrm{NAD}^{+}$concentrations, we propose that they are rather related to $\mathrm{NAD}^{+}$binding and not to automodification with PAR. This hypothesis is further supported by the results obtained with the PARP1 $1^{\mathrm{E} 988 \mathrm{~K}}$ mutant. Interestingly, a recent study revealed a further shift of the HD towards the unfolded state upon binding of a non-hydrolysable $\mathrm{NAD}^{+}$ analogue ${ }^{27}$. Those structural changes were linked to an increased affinity of PARP1 for DNA damage. Our data support those findings and suggest an increase of disordered structures probably linked to the unfolding of the $\mathrm{HD}$ domain upon $\mathrm{NAD}^{+}$binding. Yet, we did not observe increased affinity to DNA upon $\mathrm{NAD}^{+}$ binding, but instead, the immediate dissociation of PARP1 from DNA. Even though a stabilising effect directly after $\mathrm{NAD}^{+}$ binding might still be possible, which was then immediately reversed by the following catalytic reaction, the observed stabilising effect might also be specifically caused by the $\mathrm{NAD}^{+}$analogue used by Langelier et al. ${ }^{27}$, as this might have a slightly different binding mechanisms than naturally occurring NAD ${ }^{+}$. The binding mechanisms of $\mathrm{NAD}^{+}$causing additional destabilization of the HD domain might be a key step for further activation of PARP1 and PAR elongation. This mechanism could explain why PAR elongation rates remarkably exceed initiation rates $^{50}$.

Interestingly, we observed similar structural changes of PARP1 upon addition of the PARP inhibitors. This suggests that, besides $\mathrm{NAD}^{+}$binding, also PARP inhibitor binding results in a destabilization of the HD. Whereas inhibitors mimic the nicotinamide moiety of $\mathrm{NAD}^{+}$and solely bind to the nicotinamide-binding pocket within the ART domain of PARP1, $\mathrm{NAD}^{+}$also binds to the phosphate and adenine-ribose-binding site. The impact on PARP1's structure was more pronounced for olaparib compared with veliparib, which is the more potent inhibitor and the sterically more demanding molecule. Therefore, our data suggest that binding of molecules to the nicotinamide-binding pocket is sufficient for structural changes of PARP1, but is likely to depend on their size and binding strength.

In our ATR-FTIR spectroscopic approach, DNA strand break models were immobilised via streptavidin at the crystal surface. In principle, streptavidin may undergo structural changes during measurements as well, which could not be distinguished from structural changes of PARP1. However, such changes are rather unlikely, since it is known that streptavidin is an extremely stable protein $^{66}$, and we reported previously that even elevated temperatures or high concentrations of detergents did not result in significant structural changes of streptavidin ${ }^{36}$. Furthermore, we can exclude that PARylation of streptavidin induced the structural changes at the band position $\sim 1640 \mathrm{~cm}^{-1}$, since changes at this band position were also observed upon application of PARP inhibitors instead of $\mathrm{NAD}^{+}$. Finally, the controls included in this study, e.g. analysis of potential $\mathrm{NAD}^{+}$-induced effects in the presence of PARP inhibitor or analysis of PARP $1{ }^{\mathrm{E} 988 \mathrm{~K}}$, provide strong evidence for PARP1-specific effects.

The concept of a PARP1 trapping mechanism is based on findings showing that PARP1 catalytic inhibition showed higher cytotoxicity than PARP1 depletion. The trapped PARP1 complex at DNA lesions prevents DNA metabolic processes and thereby induces cell death ${ }^{59}$. The mechanism behind this is still controversial. Two non-mutually exclusive hypotheses exist: on the one hand, it is suggested that an allosteric binding mechanism increases PARP1's affinity for $\mathrm{DNA}^{9,67}$, on the other hand, the mere inhibition of catalytic activity, which inhibits PARylation- dependent dissociation, may stabilise PARP1 on DNA ${ }^{1,60}$. Performing a competitive DNA-binding experiment, we provide evidence for the second hypothesis, i.e. while DNA binding itself was not affected by the presence of inhibitor, inhibition of PARP1 activity prevented the resulting dissociation of PARP1 from DNA.

In conclusion, this study provides insights into the dynamic and overlapping processes of PARP1-dependent PARylation, including activation at DNA strand breaks, $\mathrm{NAD}^{+}$binding, PARylation and dissociation of PARP1 from DNA. The direct and label-free spectroscopic tracking of the enzymatic reaction enabled high sensitivity and reproducibility, and revealed information on kinetics as well as on the tightly controlled structural changes of PARP1. Since PARP1 is a promising target for precision therapy by selectively treating DNA repair-deficient cancers, the detailed examination of the underlying molecular processes of PARP1-dependent PARylation can give us a starting point to improve our methodologies and develop future therapies. Finally, the ATR-FTIR spectroscopic approach not only provides a platform to study molecular processes of PARP1-dependent PARylation but has also the potential to unravel the enzymatic mechanisms of other enzymes involved in DNA metabolism as well as to provide a deeper understanding of how posttranslational modifications in general control enzymatic functions and protein structures.

\section{Methods}

Purification of PARP1. PARP1 was purified as described previously ${ }^{35,68}$, with some modifications. Briefly, bacterial pellets [E. coli strain Rosetta 2 (DE3)] from 21 cultures were resuspended in lysis buffer (25 mM HEPES pH 8.0, $500 \mathrm{mM} \mathrm{NaCl}$, $0.5 \mathrm{mM}$ DTT, $10 \mathrm{mM}$ benzamide), supplemented with $0.1 \%$ NP-40, Complete EDTA-free protease inhibitor cocktail (Roche) and $1 \mathrm{mg} / \mathrm{ml}$ lysozyme (SigmaAldrich), and were sonicated four times for $20 \mathrm{~s}$ each. Then, $5 \mu \mathrm{g} / \mathrm{ml}$ DNase I (Roche) was added and the lysate was incubated for $1 \mathrm{~h}$. Cell debris was removed by centrifugation $(68,000 \times g$ for $2 \mathrm{~h}$ ), the supernatant was filtered through a $0.2-\mu \mathrm{m}$ syringe filter (Corning) and loaded onto a HisTrap HPcolumn (GE Healthcare). After washing with $10 \mathrm{ml}$ of $1 \mathrm{M} \mathrm{NaCl}$, PARP1 was eluted with $30 \mathrm{ml}$ of $500 \mathrm{mM}$ imidazole. The elution fraction was diluted to a final $\mathrm{NaCl}$ concentration of 375 $\mathrm{mM}$ with no-salt heparin buffer (50 mM Na-phosphate $\mathrm{pH} 7.0 ; 1 \mathrm{mM}$ EDTA) and loaded onto a heparin HP column (GE Healthcare). PARP1 was eluted by gradually increasing the $\mathrm{NaCl}$ concentration up to $1 \mathrm{M}(30 \mathrm{ml})$. PARP1 containing fractions were concentrated and buffer was exchanged ( $50 \mathrm{mM}$ Tris pH $8,150 \mathrm{mM} \mathrm{NaCl}$, $0.5 \mathrm{mM}$ DTT) via centrifugal filters (Amicon Ultra 15, $10 \mathrm{kDa}$ MWCO). PARP1 was further purified by size-exclusion chromatography using a HiLoad 16/600 Superdex 200 column (GE Healthcare) $(50 \mathrm{mM}$ Tris pH 8, $150 \mathrm{mM} \mathrm{NaCl}, 0.5 \mathrm{mM}$ DTT). The flow rate was set to $0.3 \mathrm{ml} / \mathrm{min}$, and pure PARP1 containing fractions were concentrated (Amicon Ultra $4,10 \mathrm{kDa}$ MWCO) and stored at $-80^{\circ} \mathrm{C}$.

ATR-FTIR spectroscopy. Real-time ATR-FTIR spectroscopic measurements were performed as described previously ${ }^{35,36}$, with some adaptations. A Vertex $70 \mathrm{~V}$ spectrometer (Bruker) was equipped with a BioATR cell II (Bruker), which contained a multi-reflection silicon crystal. The penetration depth of the IR beam into the sample depends on the wavenumber, refractive indices, and angle of incidence, and is $\sim 850 \mathrm{~nm}$ (calculated for $1000 \mathrm{~cm}^{-1}, \mathrm{n}_{\text {sample }}=1.5, \mathrm{n}_{\text {silicon }}=3.4$, and $45^{\circ}$ angle of incidence). The spectral resolution was set to $4 \mathrm{~cm}^{-1}$, and for each spectrum 100 scans were performed. The temperature of the crystal was controlled via an external water bath and set to $20^{\circ} \mathrm{C}$. Unless stated otherwise, measurements were performed in Tris buffer $(50 \mathrm{mM}$ Tris $\mathrm{pH} 7.4,150 \mathrm{mM} \mathrm{NaCl})$.

Surface passivation of the ATR crystal: The modification of the crystal surface was performed as described ${ }^{35,36}$. Briefly, the surface was activated by treatment with $\mathrm{H}_{2} \mathrm{SO}_{4}$ and $\mathrm{H}_{2} \mathrm{O}_{2}$. Next, the crystal was heated to $50{ }^{\circ} \mathrm{C}$ and $20 \mathrm{mg} / \mathrm{ml}$ PEG-silane-biotin linker ( $5 \mathrm{kDa}$, Rapp Polymere) in $30 \mathrm{mM}$ sodium acetate solution ( $\mathrm{pH} 5.5$ ) was added. After $30 \mathrm{~min}$ of incubation, the temperature was adjusted to $20^{\circ} \mathrm{C}$, and the biotin-PEG-silane linker solution was allowed to dry to achieve condensation of the silane groups. Then, the surface was washed thoroughly with Tris buffer and incubated in buffer for 1-2 h. This washing step was repeated and after 20 min of incubation in Tris buffer, the spectrum of the modified surface was set as background.

Immobilisation of biotinylated DNA strand break models: Ten to twenty picomole of annealed biotinylated DNA $\left(\mathrm{DNA}_{\text {blunt }}, \mathrm{DNA}_{3^{\prime} \mathrm{P}}, \mathrm{DNA}_{5^{\prime} \mathrm{P}}\right.$ or $\left.\mathrm{DNA}_{\text {nick }}\right)$ were mixed with $10 \mathrm{pmol}$ of streptavidin in $10 \mu \mathrm{l}$ Tris buffer. The sample was applied to the biotinylated surface and incubated until the maximum signal was reached. This procedure was repeated until no further increase of signal was observed. The crystal was washed thoroughly with Tris buffer and the IR signal of immobilised DNA was set as background. 
Analysis of DNA binding and PARylation of PARP1: First, $20 \mu \mathrm{l}$ of $2 \mu \mathrm{M}$ PARP1 in Tris buffer was added to the immobilised DNA. For technical reasons, measurements were started 5-10 s after addition of PARP1. Binding was followed for $20 \mathrm{~min}$ by taking spectra in time intervals of $1 \mathrm{~min}$. Next, unbound PARP1 was removed by exchanging the buffer once. After 20 min of equilibration, a spectrum was recorded, which was used for structural analysis. To initiate the PARylation reaction by PARP1, $150 \mu \mathrm{l}$ reaction buffer at the respective $\mathrm{NAD}^{+}$concentration $(0 ; 1 ; 10 ; 100 ; 500 \mu \mathrm{M})$ was added. Immediately after the addition, spectra were recorded for $80 \mathrm{~min}$ in 1-min time intervals. For technical reasons, the first recording of IR spectroscopic data started $1-2 \mathrm{~s}$ after addition of $\mathrm{NAD}^{+}$. After 80 min, loosely bound PARP1 was removed by washing thoroughly with $\mathrm{NaCl}$ buffer (50 mM Tris pH 7.4, $1 \mathrm{M} \mathrm{NaCl}$ ). Finally, PARP1 was removed by washing thoroughly with SDS buffer (50 mM Tris pH 7.4, $150 \mathrm{mM} \mathrm{NaCl}, 1 \%$ SDS)

Analysis of inhibitor binding: First, $20 \mu$ of $2 \mu$ M PARP1 in Tris buffer $(50 \mathrm{mM}$ Tris $\mathrm{pH} 7.8,150 \mathrm{mM} \mathrm{NaCl}, 5 \mathrm{mM} \mathrm{MgCl}$ ) was added to the immobilised $\mathrm{DNA}_{\text {blunt. }}$ After $20 \mathrm{~min}$, a spectrum was recorded (designated '-Inhibitor'). Then, $15 \mu \mathrm{l}$ of supernatant was removed, and $20 \mu \mathrm{l}$ of inhibitor [veliparib or olaparib (both from Selleckchem)] was added to a final concentration of $10 \mu \mathrm{M}$. After $20 \mathrm{~min}$, a spectrum was recorded (designated ' + Inhibitor'). To analyse the inhibitor potency $50 \mu \mathrm{l} \mathrm{NAD}{ }^{+}$was added to a final concentration of $100 \mu \mathrm{M}$, and spectra were recorded for $30 \mathrm{~min}$ in 1-min time intervals. The impact of inhibitor on PARP1 binding to DNA was analysed by competitive binding, i.e., by adding free $\mathrm{DNA}_{\text {blunt }}$ to a final concentration of $2 \mu \mathrm{M}$ to PARP1 bound to immobilised DNA blunt in the presence or absence of $10 \mu \mathrm{M}$ olaparib. Spectra were measured for $50 \mathrm{~min}$ in 2-min time intervals

Spectral analysis: To analyse the binding of PARP1 to different DNA strand break models the IR spectrum of immobilised DNA was set as background. Binding kinetics were evaluated by tracking the intensity increase of the amide I band $\left(1645 \mathrm{~cm}^{-1}\right)$ over time. Data were fitted via the following mono-exponential function: $y=y_{0}+\left(y_{P}-y_{0}\right) \cdot\left(1-e^{-k x}\right)$; $y_{0}$ is the $y$ intercept, i.e., the $y$ value at which $x$ (time) is zero, $y_{P}\left(y_{\text {Plateau }}\right)$ is the $y$ value reached at infinite times and $k$ is the rate constant $\left(\mathrm{min}^{-1}\right)$. It is important to note that the experimental approach limits the calculation of absolute values of rate constants, as the exact amount of immobilised DNA is an unknown parameter. Furthermore, due to the fast binding of PARP1 to the immobilised DNA, a time gap of some seconds between addition of PARP1 and the start of data acquisition cannot be avoided for technical reasons. Nevertheless, the method is highly suitable for a relative comparison of binding kinetics. Binding stoichiometries were evaluated by normalising the PARP1 signal to the signal of immobilised DNA. To do this, the intensity of the amide I band of PARP1 $\left(1645 \mathrm{~cm}^{-1}\right)$ was divided by the intensity of the band of the anti-symmetric phosphate vibration of DNA $\left(1220 \mathrm{~cm}^{-1}\right)$. To correct for different DNA lengths and varying numbers of phosphate groups, the values calculated were further multiplied by the respective number of phosphate groups. PARP1 dissociation upon $\mathrm{NAD}^{+}$addition was analysed via the intensity of the amide II band $(1548 \mathrm{~cm}$ ${ }^{-1}$ ) and fitted via the following mono-exponential function:

$y=\left(y_{0}-y_{P}\right) e^{-k x}+y_{P}$. PAR formation upon $\mathrm{NAD}^{+}$addition was analysed via the anti-symmetric phosphate vibration of PAR $\left(1236 \mathrm{~cm}^{-1}\right)$ and fitted via the following mono-exponential function: $y=y_{0}+\left(y_{P}-y_{0}\right) \cdot\left(1-e^{-k x}\right)$.

Reaction-induced difference spectroscopy of the amide I band: The amide I band $\left(\sim 1710-1595 \mathrm{~cm}^{-1}\right)$ within the IR spectrum of proteins arises mainly from $\mathrm{C}=\mathrm{O}$ stretching vibrations of the polypeptide backbone and is sensitive to protein secondary structures. Distinct frequencies within the amide I band can be assigned to distinct secondary structures, such as $\alpha$-helices $\left(1648-1657 \mathrm{~cm}^{-1}\right), 3_{10}$-helices $\left(1660-1666 \mathrm{~cm}^{-1}\right)$, disordered structures $\left(1642-1657 \mathrm{~cm}^{-1}\right)$, $\beta$-sheets $(1623-1641$ and $\left.1674-1695 \mathrm{~cm}^{-1}\right), \beta$-turns $\left(1662-1686 \mathrm{~cm}^{-1}\right)$ and extended $\beta$-sheets/amyloid aggregates $\left(1630-1611 \mathrm{~cm}^{-1}\right)^{49,55}$. Therefore, large proteins containing several secondary structures commonly display a single, broad amide I band, which is composed of overlapping amide I band components. Several techniques exist to resolve those structural components such as second-derivative analysis or Fourier self-deconvolution. Reaction-induced difference spectroscopy enables detection of subtle structural changes within proteins during protein reactions. After reaction induction (e.g. substrate addition), absorbance changes of proteins are monitored. Those absorbance changes are usually small compared to total absorbance. Therefore, difference spectra of two states of a protein are calculated. This eliminates all vibrational modes that do not change, and thereby resolves structural changes. Thus, remaining positive and negative bands within a difference spectrum represent structural components, which are characteristic for the respective state of a protein. To evaluate structural changes of PARP1 upon binding to different DNA strand break models or after addition of $\mathrm{NAD}^{+}$or pharmacological PARP inhibitors, the respective amide I bands were first corrected for different water contents ( $\mathrm{O}-\mathrm{H}$ bending vibration overlays amide I band region). In a second step, a baseline correction between 1710 and $1595 \mathrm{~cm}^{-1}$ was performed. Then, amide I bands were normalised to the area under the curve and, finally, difference spectra were calculated.

Gel-based assay for analysis of PARP1 automodification. PARP1 $(0.5 \mu \mathrm{M})$ was incubated with $\mathrm{DNA}_{\text {blunt }}, \mathrm{DNA}_{3^{\prime} \mathrm{P}}$, $\mathrm{DNA}_{5^{\prime} \mathrm{P}}$ or $\mathrm{DNA}_{\text {nick }}(10 \mu \mathrm{M})$ for $15 \mathrm{~min}$ in Tris buffer $(50 \mathrm{mM}$ Tris $\mathrm{pH} 7.4,150 \mathrm{mM} \mathrm{NaCl})$ at room temperature. PARylation was started by the addition of a mixture of unlabelled and TAMRA-labelled NAD ${ }^{+}$ $(20: 1)$ to a final concentration of $100 \mu \mathrm{M}^{69}$. PARylation was stopped by adding SDS loading dye and heating for $5 \mathrm{~min}$ at $95^{\circ} \mathrm{C}$. PARylation of PARP1 activated at different DNA strand break models was stopped after $5 \mathrm{~min}$. For comparison of PARP1 and PARP1 ${ }^{\text {E988K }}$ (activated at DNA blunt $_{\text {) }}$ PARylation was stopped after 1, 2 5,10 and $30 \mathrm{~min}$. The extent of automodification was analysed via SDS-PAGE (4-20\% precast polyacrylamide gel, Bio-Rad) and subsequent fluorescence detection.

Gel-based assay for analysis of streptavidin PARylation. Streptavidin $(2 \mu \mathrm{M})$ was pre-incubated with biotinylated or non-biotinylated DNA $(2 \mu \mathrm{M})$ in Tris buffer (50 mM Tris $\mathrm{pH} 7.4,150 \mathrm{mM} \mathrm{NaCl}$ ) for $15 \mathrm{~min}$ at room temperature. Then, PARP1 $(1 \mu \mathrm{M})$ was added, and binding of PARP1 to DNA was allowed for $20 \mathrm{~min}$ Next, PARylation was started by addition of $\mathrm{NAD}^{+}$to a final concentration of 500 $\mu \mathrm{M}$. To exclude PARylation of DNA or an unspecific post-PARylation effect, streptavidin $(2 \mu \mathrm{M})$ or biotinylated DNA $(2 \mu \mathrm{M})$ were added after $60 \mathrm{~min}$ of PARylation as indicated, and samples were incubated for another $15 \mathrm{~min}$ at room temperature. Finally, PARylation was stopped by the addition of SDS loading dye and subsequent heating for $5 \mathrm{~min}$ at $95^{\circ} \mathrm{C}$. PARylation was analysed by SDS-PAGE followed by western blotting and immunodetection of PAR $\left(10 \mathrm{H}\right.$ antibody ${ }^{70}$, purified from hybridoma cells, 1:250) and PARP1 (CII10 antibody ${ }^{71}$, purified from hybridoma cells, 1:250).

Gel-based assay for analysis of DNA PARylation. PARP1 $(1 \mu \mathrm{M})$ was incubated with Cy5-labelled $\mathrm{DNA}_{3^{\prime} \mathrm{P}}(0.1 \mu \mathrm{M})$ for $20 \mathrm{~min}$ at room temperature. The PARylation reaction was started by the addition of a mixture of unlabelled and TAMRA-labelled $\mathrm{NAD}^{+69}$ in ratio of 10:1 to a final concentration of $100 \mu \mathrm{M}$. After 30 min, PARylation was stopped by adding SDS to a final concentration of $1 \%$. PARylation of DNA was analysed on a $20 \%$ sequencing gel followed by fluorescence detection.

Enzymatic synthesis of ${ }^{13} \mathrm{C}^{15} \mathrm{~N}-\mathrm{NAD}{ }^{+}$. Analysis of structural changes of PARP1 upon PARylation was challenging as two vibrational modes of PAR (1649 and $\left.1605 \mathrm{~cm}^{-1}\right)$ overlap the structure-sensitive amide I region $\left(\sim 1710-1595 \mathrm{~cm}^{-1}\right)$. Therefore, isotopically labelled $\mathrm{NAD}^{+}$was used. The enzymatic synthesis of isotopically labelled $\mathrm{NAD}^{+}$was performed according to an adapted protocol from $\mathrm{R}$. Martello (PhD thesis, University of Konstanz, 2013, http://nbn-resolving.de/urn: nbn:de:bsz:352-230252) and Balducci et al. ${ }^{72} .{ }^{13} \mathrm{C}^{15} \mathrm{~N}-\mathrm{ATP}$ (Sigma-Aldrich) at a concentration of $1 \mathrm{mM}$ was incubated for $1 \mathrm{~h}$ at RT together with $1 \mathrm{mM}$ NMN (Sigma-Aldrich), $25 \mathrm{mU}$ NMNAT1 (gift of M. Ziegler, University of Bergen, Norway) and $2.5 \mathrm{U}$ inorganic pyrophosphatase from yeast (Roche) in $200 \mu \mathrm{l}$ buffer (50 mM Tris pH 7.4; $150 \mathrm{mM} \mathrm{NaCl} ; 10 \mathrm{mM} \mathrm{MgCl}_{2}$ ). Enzymes were removed by centrifugal filters [Nanosep, $10 \mathrm{kDa}$ MWCO (Pall)]. To remove trace amounts of glycerol, which was used for storage of the filters but interferes with infrared spectroscopic analysis, centrifugal filters were first washed three times with $500 \mu \mathrm{l}$ MilliQ before applying the enzymatic mixture. Conversion of ATP to $\mathrm{NAD}^{+}$was analysed by HPLC equipped with a Hydro-RP $80 \mathrm{~A}$ column $(250 \times 4.6 \mathrm{~mm}, 4$ micron) at a flow rate of $0.5 \mathrm{ml} / \mathrm{min}$ (solvent A: $8 \mathrm{mM}$ ammonium acetate; solvent B: acetonitrile). The HPLC programme was set as follows: 0 min 1\% B; 15 min 10\% B; $30 \min 15 \%$ B; $40 \min 100 \%$ B; 50 min $100 \%$ B; 51 min $1 \%$ B; $65 \operatorname{min~} 1 \%$ B.

Reporting summary. Further information on research design is available in the Nature Research Reporting Summary linked to this article.

\section{Data availability}

Source data of Figs. 2b, c, d, 3c, d, 4b, c, 5a, d, 6a, b and Supplementary Figs. 1e, 2c, d, 3b c, d, $4 \mathrm{a}, \mathrm{d}, 5,6 \mathrm{~b}, \mathrm{c}, \mathrm{d}, \mathrm{f}, 7 \mathrm{a}, \mathrm{b}$ are provided as Source Data file. Further raw data and unprocessed data can be provided by the corresponding authors upon reasonable request.

Received: 4 September 2019; Accepted: 27 March 2020;

Published online: 01 May 2020

\section{References}

1. Rudolph, J., Mahadevan, J., Dyer, P. \& Luger, K. Poly(ADP-ribose) polymerase 1 searches DNA via a 'monkey bar' mechanism. eLife 7, e37818 (2018).

2. Ray Chaudhuri, A. \& Nussenzweig, A. The multifaceted roles of PARP1 in DNA repair and chromatin remodelling. Nat. Rev. Mol. Cell Biol. 18, 610-621 (2017)

3. Gibbs-Seymour, I., Fontana, P., Rack, J. G. M. \& Ahel, I. HPF1/C4orf27 is a PARP-1-interacting protein that regulates PARP-1 ADP-ribosylation activity. Mol. Cell 62, 432-442 (2016).

4. Bonfiglio, J. J. et al. Serine ADP-ribosylation depends on HPF1. Mol. Cell 65 , 932-940.e936 (2017).

5. Jungmichel, S. et al. Proteome-wide identification of Poly(ADP-Ribosyl) ation targets in different genotoxic stress responses. Mol. Cell 52, 272-285 (2013). 
6. Zhang, Y., Wang, J., Ding, M. \& Yu, Y. Site-specific characterization of the Asp- and Glu-ADP-ribosylated proteome. Nat. Methods 10, 981 (2013).

7. Gibson, B. A. et al. Chemical genetic discovery of PARP targets reveals a role for PARP-1 in transcription elongation. Science 353, 45-50 (2016).

8. Langelier, M.-F., Riccio, A. A. \& Pascal, J. M. PARP-2 and PARP-3 are selectively activated by $5^{\prime}$ phosphorylated DNA breaks through an allosteric regulatory mechanism shared with PARP-1. Nucleic Acids Res. 42, 7762-7775 (2014).

9. Murai, J. et al. Trapping of PARP1 and PARP2 by clinical PARP inhibitors. Cancer Res. 72, 5588-5599 (2012).

10. Satoh, M. S. \& Lindahl, T. Role of poly(ADP-ribose) formation in DNA repair. Nature 356, 356-358 (1992).

11. Steffen J. D., McCauley M. M. \& Pascal J. M. Fluorescent sensors of PARP-1 structural dynamics and allosteric regulation in response to DNA damage. Nucleic Acids Res. 20, 9771-9783 (2016).

12. Chambon, P., Weill, J. D. \& Mandel, P. Nicotinamide mononucleotide activation of a new DNA-dependent polyadenylic acid synthesizing nuclear enzyme. Biochem. Biophys. Res. Commun. 11, 39-43 (1963).

13. Langelier, M. F., Planck, J. L., Roy, S. \& Pascal, J. M. Crystal structures of poly (ADP-ribose) polymerase-1 (PARP-1) zinc fingers bound to DNA: structural and functional insights into DNA-dependent PARP-1 activity. J. Biol. Chem. 286, 10690-10701 (2011).

14. Eustermann, S. et al. Structural basis of detection and signaling of DNA singlestrand breaks by human PARP-1. Mol. Cell 60, 742-754 (2015).

15. Lonskaya, I. et al. Regulation of poly(ADP-ribose) polymerase-1 by DNA structure-specific binding. J. Biol. Chem. 280, 17076-17083 (2005).

16. D'Silva, I. et al. Relative affinities of poly(ADP-ribose) polymerase and DNAdependent protein kinase for DNA strand interruptions. Biochimica et. biophysica acta 1430, 119-126 (1999).

17. Kun, E., Kirsten, E., Mendeleyev, J. \& Ordahl, C. P. Regulation of the enzymatic catalysis of Poly(ADP-ribose) polymerase by dsDNA, polyamines, Mg2+, Ca2+, Histones H1 and H3, and ATP. Biochemistry 43, 210-216 (2004).

18. Ali, A. A. E. et al. The zinc-finger domains of PARP1 cooperate to recognize DNA strand breaks. Nat. Struct. Amp; Mol. Biol. 19, 685 (2012).

19. Eustermann, S. et al. The DNA-binding domain of human PARP-1 interacts with DNA single-strand breaks as a monomer through its second zinc finger. J. Mol. Biol. 407, 149-170 (2011).

20. Karlberg, T., Langelier, M.-F., Pascal, J. M. \& Schüler, H. Structural biology of the writers, readers, and erasers in mono- and poly(ADP-ribose) mediated signaling. Mol. Asp. Med. 34, 1088-1108 (2013).

21. Langelier, M.-F., Ruhl, D. D., Planck, J. L., Kraus, W. L. \& Pascal, J. M. The Zn3 domain of human Poly(ADP-ribose) polymerase-1 (PARP-1) functions in both DNA-dependent Poly(ADP-ribose) synthesis activity and chromatin compaction. J. Biol. Chem. 285, 18877-18887 (2010).

22. Langelier, M.-F., Planck, J. L., Roy, S. \& Pascal, J. M. Structural basis for DNA damage-dependent Poly(ADP-ribosyl)ation by Human PARP-1. Science 336, 728-732 (2012).

23. Loeffler, P. A. et al. Structural studies of the PARP-1 BRCT domain. BMC Struct. Biol. 11, 37-37 (2011).

24. Barkauskaite, E., Jankevicius, G. \& Ahel, I. Structures and mechanisms of enzymes employed in the synthesis and degradation of PARP-dependent protein ADP-ribosylation. Mol. Cell 58, 935-946 (2015).

25. Steffen, J. D., Brody, J. R., Armen, R. S. \& Pascal, J. M. Structural implications for selective targeting of PARPs. Front. Oncol. 3, 301 (2013).

26. Langelier, M.-F. \& Pascal, J. M. PARP-1 mechanism for coupling DNA damage detection to poly(ADP-ribose) synthesis. Curr. Opin. Struct. Biol. 23, 134-143 (2013).

27. Langelier, M. F., Zandarashvili, L., Aguiar, P. M., Black, B. E. \& Pascal, J. M. $\mathrm{NAD}(+)$ analog reveals PARP-1 substrate-blocking mechanism and allosteric communication from catalytic center to DNA-binding domains. Nat. Commun. 9, 844 (2018).

28. Dawicki-McKenna Jennine, M. et al. PARP-1 activation requires local unfolding of an autoinhibitory domain. Mol. Cell 60, 755-768 (2015).

29. Mendoza-Alvarez, H. \& Alvarez-Gonzalez, R. Poly(ADP-ribose) polymerase is a catalytic dimer and the automodification reaction is intermolecular. J. Biol. Chem. 268, 22575-22580 (1993).

30. Pion, E. et al. DNA-induced dimerization of poly(ADP-ribose) polymerase-1 triggers its activation. Biochemistry 44, 14670-14681 (2005).

31. Lilyestrom, W., van der Woerd, M. J., Clark, N. \& Luger, K. Structural and biophysical studies of human PARP-1 in complex with damaged DNA. J. Mol. Biol. 395, 983-994 (2010).

32. Liu, L. et al. PARP1 changes from three-dimensional DNA damage searching to one-dimensional diffusion after auto-PARylation or in the presence of APE1. Nucleic Acids Res. 45, 12834-12847 (2017).

33. Goormaghtigh, E., Raussens, V. \& Ruysschaert, J. M. Attenuated total reflection infrared spectroscopy of proteins and lipids in biological membranes. Biochimica et. biophysica acta 1422, 105-185 (1999).
34. Nyquist, R. M., Ataka, K. \& Heberle, J. The molecular mechanism of membrane proteins probed by evanescent infrared waves. Chembiochem $\mathbf{5}$, 431-436 (2004).

35. Krüger A., Stier A., Fischbach A., Bürkle A., Hauser K. \& Mangerich A. Interactions of p53 with poly(ADP-ribose) and DNA induce distinct changes in protein structure as revealed by ATR-FTIR spectroscopy. Nucleic Acids Res. 47, 4843-4858 (2019).

36. Krüger, A., Bürkle, A., Mangerich, A. \& Hauser, K. A combined approach of surface passivation and specific immobilization to study biomolecules by ATR-FTIR spectroscopy. Biomed. Spectrosc. Imaging 7, 25-33 (2018).

37. Sukhanova, M. V. et al. Single molecule detection of PARP1 and PARP2 interaction with DNA strand breaks and their poly(ADP-ribosyl)ation using high-resolution AFM imaging. Nucleic Acids Res. 44, e60-e60 (2016).

38. Banyay, M., Sarkar, M. \& Gräslund, A. A library of IR bands of nucleic acids in solution. Biophysical Chem. 104, 477-488 (2003).

39. Langelier, M. F., Riccio, A. A. \& Pascal, J. M. PARP-2 and PARP-3 are selectively activated by 5 ' phosphorylated DNA breaks through an allosteric regulatory mechanism shared with PARP-1. Nucleic Acids Res. 42, 7762-7775 (2014).

40. Langelier, M.-F., Eisemann, T., Riccio, A. A. \& Pascal, J. M. PARP family enzymes: regulation and catalysis of the poly(ADP-ribose) posttranslational modification. Curr. Opin. Struct. Biol. 53, 187-198 (2018).

41. Pascal, J. M. The comings and goings of PARP-1 in response to DNA damage. DNA Repair 71, 177-182 (2018).

42. Bayer, E. A., Ehrlich-Rogozinski, S. \& Wilchek, M. Sodium dodecyl sulfatepolyacrylamide gel electrophoretic method for assessing the quaternary state and comparative thermostability of avidin and streptavidin. Electrophoresis $\mathbf{1 7}$ 1319-1324 (1996).

43. Waner, M. J., Navrotskaya, I., Bain, A., Oldham, E. D. \& Mascotti, D. P. Thermal and sodium dodecylsulfate induced transitions of streptavidin. Biophysical J. 87, 2701-2713 (2004).

44. Talhaoui, I. et al. Poly(ADP-ribose) polymerases covalently modify strand break termini in DNA fragments in vitro. Nucleic Acids Res. 44, 9279-9295 (2016).

45. Munnur, D. \& Ahel, I. Reversible mono-ADP-ribosylation of DNA breaks. FEBS J. 284, 4002-4016 (2017).

46. Belousova, E. A., Ishchenko, AA. \& Lavrik, O. I. Dna is a new target of Parp3. Sci. Rep. 8, 4176-4176 (2018).

47. Zarkovic, G. et al. Characterization of DNA ADP-ribosyltransferase activities of PARP2 and PARP3: new insights into DNA ADP-ribosylation. Nucleic Acids Res. 46, 2417-2431 (2018).

48. Fischbach, A. et al. The C-terminal domain of p53 orchestrates the interplay between non-covalent and covalent poly(ADP-ribosyl)ation of p53 by PARP1. Nucleic Acids Res. 46, 804-822 (2018).

49. Barth, A. Infrared spectroscopy of proteins. Biochimica et. Biophysica Acta 1767, 1073-1101 (2007).

50. Alemasova, E. E. \& Lavrik, O. I. Poly(ADP-ribosyl)ation by PARP1: reaction mechanism and regulatory proteins. Nucleic Acids Res. 47, 3811-3827 (2019).

51. Marsischky, G. T., Wilson, B. A. \& Collier, R. J. Role of glutamic acid 988 of human poly-ADP-ribose polymerase in polymer formation. Evidence for active site similarities to the ADP-ribosylating toxins. J. Biol. Chem. 270 3247-3254 (1995).

52. Rolli, V., O'Farrell, M., Menissier-de Murcia, J. \& de Murcia, G. Random mutagenesis of the poly(ADP-ribose) polymerase catalytic domain reveals amino acids involved in polymer branching. Biochemistry 36, 12147-12154 (1997).

53. Beneke, S., Scherr, A. L., Ponath, V., Popp, O. \& Bürkle, A. Enzyme characteristics of recombinant poly(ADP-ribose) polymerases-1 of rat and human origin mirror the correlation between cellular poly(ADP-ribosyl)ation capacity and species-specific life span. Mechanisms Ageing Dev. 131, 366-369 (2010).

54. Rank, L. et al. Analyzing structure-function relationships of artificial and cancer-associated PARP1 variants by reconstituting TALEN-generated HeLa PARP1 knock-out cells. Nucleic Acids Res. 44, 10386-10405 (2016).

55. Yang, H., Yang, S., Kong, J., Dong, A. \& Yu, S. Obtaining information about protein secondary structures in aqueous solution using Fourier transform IR spectroscopy. Nat. Protoc. 10, 382-396 (2015).

56. Chirgadze, Y. N. \& Nevskaya, N. A. Infrared spectra and resonance interaction of amide-I vibration of the paraellel-chain pleated sheets. Biopolymers 15, 627-636 (1976).

57. Krimm, S. \& Bandekar, J. Vibrational spectroscopy and conformation of peptides, polypeptides, and proteins. Adv. Protein Chem. 38, 181-364 (1986).

58. Pommier, Y., O'Connor, M. J. \& de Bono, J. Laying a trap to kill cancer cells: PARP inhibitors and their mechanisms of action. Sci. Transl. Med. 8, 362ps317-362ps317 (2016).

59. Shen, Y., Aoyagi-Scharber, M. \& Wang, B. Trapping Poly(ADP-Ribose) polymerase. J. Pharmacol. Exp. therapeutics 353, 446-457 (2015). 
60. Hopkins, T. A. et al. Mechanistic dissection of PARP1 trapping and the impact on in vivo tolerability and efficacy of PARP inhibitors. Mol. Cancer Res. 13, 1465-1477 (2015).

61. Wei, H. \& Yu, X. Functions of PARylation in DNA damage repair pathways. Genomics, Proteom. Bioinforma. 14, 131-139 (2016).

62. Liu, C., Vyas, A., Kassab, M. A., Singh, A. K. \& Yu, X. The role of poly ADPribosylation in the first wave of DNA damage response. Nucleic Acids Res. 45, 8129-8141 (2017).

63. Weinfeld, M., Mani, R. S., Abdou, I., Aceytuno, R. D. \& Glover, J. N. M. Tidying up loose ends: the role of polynucleotide kinase/phosphatase in DNA strand break repair. Trends Biochem. Sci. 36, 262-271 (2011).

64. Menissier de Murcia, J. et al. Functional interaction between PARP-1 and PARP-2 in chromosome stability and embryonic development in mouse. EMBO J. 22, 2255-2263 (2003).

65. Gagne, J. P. et al. Proteome-wide identification of poly(ADP-ribose) binding proteins and poly(ADP-ribose)-associated protein complexes. Nucleic Acids Res. 36, 6959-6976 (2008).

66. Kurzban, G. P., Bayer, E. A., Wilchek, M. \& Horowitz, P. M. The quaternary structure of streptavidin in urea. J. Biol. Chem. 266, 14470-14477 (1991).

67. Murai, J. et al. Stereospecific PARP trapping by BMN 673 and comparison with olaparib and rucaparib. Mol. Cancer Therapeut. 13, 433-443 (2014)

68. Langelier, M. F., Planck, J. L., Servent, K. M. \& Pascal, J. M. Purification of human PARP-1 and PARP-1 domains from Escherichia coli for structural and biochemical analysis. Methods Mol. Biol. 780, 209-226 (2011).

69. Wang, Y., Rosner, D., Grzywa, M. \& Marx, A. Chain-terminating and clickable $\mathrm{NAD}(+)$ analogues for labeling the target proteins of ADPribosyltransferases. Angew. Chem. 53, 8159-8162 (2014).

70. Kawamitsu, H. et al. Monoclonal antibodies to poly(adenosine diphosphate ribose) recognize different structures. Biochemistry 23, 3771-3777 (1984).

71. Lamarre, D. et al. Structural and functional analysis of poly(ADP ribose) polymerase: an immunological study. Biochimica et. biophysica acta 950, 147-160 (1988).

72. Balducci, E. et al. Assay methods for nicotinamide mononucleotide adenylyltransferase of wide applicability. Anal. Biochem. 228, 64-68 (1995)

\section{Acknowledgements}

We thank Andreas Marx (University of Konstanz) for providing TAMRA-labelled NAD + and Anna-Lena Müller for purification of recombinant PARP1E988K. This work was supported by the German Research Foundation (DFG) through the Konstanz Research School Chemical Biology (KoRS-CB, GSC 218), the research grant MA4905/4-1, the Collaborative Research Centers 969 (CRC969, project A02) and 1214 (project A03), and by the Zukunftskolleg of the University of Konstanz. Funding for open access charge: University of Konstanz and CRC969.

\section{Author contributions}

Conceptualisation, A.K., K.H. and AM; experimental research and data analysis, A.K.; data interpretation, A.K., A.B., K.H. and A.M.; writing, A.K., K.H. and A.M.; review and editing, A.K., A.B., K.H. and A.M.

\section{Competing interests}

The authors declare no competing interests.

\section{Additional information}

Supplementary information is available for this paper at https://doi.org/10.1038/s41467 020-15858-w.

Correspondence and requests for materials should be addressed to K.H. or A.M.

Peer review information Nature Communications thanks the anonymous reviewers for their contribution to the peer review of this work. Peer review reports are available.

Reprints and permission information is available at http://www.nature.com/reprints Publisher's note Springer Nature remains neutral with regard to jurisdictional claims in published maps and institutional affiliations.

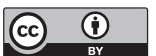

Open Access This article is licensed under a Creative Commons Attribution 4.0 International License, which permits use, sharing, adaptation, distribution and reproduction in any medium or format, as long as you give appropriate credit to the original author(s) and the source, provide a link to the Creative Commons license, and indicate if changes were made. The images or other third party material in this article are included in the article's Creative Commons license, unless indicated otherwise in a credit line to the material. If material is not included in the article's Creative Commons license and your intended use is not permitted by statutory regulation or exceeds the permitted use, you will need to obtain permission directly from the copyright holder. To view a copy of this license, visit http://creativecommons.org/ licenses/by/4.0/.

(c) The Author(s) 2020 